\title{
A comparison of perimetric results with the Medmont and Humphrey perimeters
}

\author{
J Landers, A Sharma, I Goldberg, S Graham
}

Br J Ophthalmol 2003;87:690-694

Background: The Humphrey field analyser (HFA), Humphrey-Zeiss frequency doubling perimeter, and the Medmont automated perimeter (MAP) are three commonly used automated perimeters with threshold achromatic methodologies. Visual field loss may be detected earlier with strategies that target cell lines with reduced redundancy or which suffer selective damage.

Method: To compare these three perimeters, 63 subjects who were glaucoma suspects, ocular hypertensives, glaucoma patients, or normal controls were recruited selectively. All subjects underwent testing using MAP central threshold, MAP flicker perimetry, HFA full threshold, HFA SITA perimetry, HFA short wavelength perimetry (SWAP), and frequency doubling perimetry (FDP). After visual field testing, equivalent tests were compared: MAP central threshold with HFA full threshold and HFA SITA perimetry; Medmont flicker perimetry with HFA SWAP and FDP.

Results: On analysis of the MAP central threshold a kappa statistic and an area under the receiver operator curve (AUC) of 0.90 and 0.94 , respectively, were found compared with HFA full threshold strategies, and 0.87 and 0.92 respectively, compared with HFA SITA. For MAP flicker a kappa statistic and an AUC of 0.65 and 0.81 , respectively, were found compared with HFA SWAP and 0.87 and 0.96 , respectively, compared with FDP. A quadrant analysis and comparison of mean defect between tests was also highly significant.

Conclusion: Medmont and Humphrey perimeters correlated well; both may be used for clinical and research purposes with similar confidence.

A utomated perimetry provides a reliable, accurate, and reproducible method of visual field testing. ${ }^{1-4}$ One of the most important benefits of automation has been the ability to standardise test procedures. ${ }^{5}$ Conventional static achromatic automated perimetry (AAP), however, may only show visual field losses if up to $50 \%$ of the ganglion cells are lost. ${ }^{67}$ More recently, tests of early visual field loss, such as flicker perimetry, short wavelength automated perimetry (SWAP), and frequency doubling perimetry (FDP) have detected visual field losses before achromatic perimetry. ${ }^{8-12}$

Three commonly utilised automated perimetric systems in Australia are the Humphrey field analyser (HFA), the Humphrey-Zeiss frequency doubling perimeter, and the Medmont automated perimeter (MAP). The HFA uses a hemispheric projection bowl of radius $33 \mathrm{~cm}$ with a uniform background illumination of 31.5 apostilbs (asb). A projection device presents a light stimulus at specified points in the visual field. While stimulus size may be varied, the most common used has a diameter of $0.43^{\circ}$ (Goldmann size III); it is usually white, but may be red, blue, or green. ${ }^{1}$ To test for fixation loss, a stimulus is presented at the blind spot intermittently through the test; this should yield no response if a patient is fixating correctly. In some models, patient fixation can be monitored directly by the technician using a video camera.

The HFA can be used in full threshold mode, which uses the threshold levels determined at one primary point in each quadrant as a starting level for neighbouring points. In turn, these are used as starting intensity levels for their neighbouring points, and so on. At each point, stimulus intensity is increased in $4 \mathrm{~dB}$ steps until threshold is crossed from non-seeing to seeing, and then reduced in $2 \mathrm{~dB}$ steps to check and refine the accuracy of the assessment.

Test time can be reduced by the utilisation of a more recently developed program called Swedish Interactive Thresholding Algorithm (SITA). ${ }^{13}$ This testing strategy continuously estimates both the threshold values and the measurement errors of those values using Bayesian posterior probability calculations. ${ }^{13}{ }^{14}$ Continuously modified staircase procedures are used to alter stimulus intensities at the test locations; these staircases are interrupted when measurement errors are reduced to predetermined levels. This coupled with a reduction in the number of catch trials for determination of frequencies of false positive answers and an increase in speed of stimulus presentation as permitted by patient responsiveness leads to significant reductions in test time while retaining accuracy. ${ }^{13} 14$

For short wavelength automated perimetry (SWAP), the HFA background illumination is altered to a yellow light at $100 \mathrm{~cd} / \mathrm{m}^{2}$ with the target a blue stimulus $(440 \mathrm{~nm})$, Goldmann size V ( $1.72^{\circ}$ diameter). Blue-on cell pathways can be tested in isolation when the yellow background effectively reduces the sensitivities of red and green cones. ${ }^{15}$ Johnson postulated $^{16}$ that as blue-on cells are the largest colour sensitive cells, ${ }^{17}$ they are more likely to be lost selectively in glaucoma. Furthermore, because blue-on cells have larger receptive fields and are fewer in number, ${ }^{17}$ there is less overlap than there is for red and green receptive fields. This reduced redundancy, ${ }^{16}$ postulated Johnson, allows these areas of axonal loss to be detected by SWAP before AAP. ${ }^{8}$

MAP utilises a $30 \mathrm{~cm}$ radius perimetric bowl with 164 green light emitting diodes (wavelength $565 \mathrm{~nm}$ ) acting as the stimulus. The background illuminating light source maintains an illumination of $10 \mathrm{asb}$. Unable to be varied in size or hue, each stimulus is an equivalent Goldmann size III. Fixation is monitored with stimulus points presented within the blind spot. Central fixation is not directly video monitored. ${ }^{18}$

Central threshold testing is performed in a pattern, which tests the visual field to $22^{\circ}$ from central fixation superiorly,

Abbreviations: AAP, achromatic automated perimetry; AUC, area under the receiver operator curve; FDP, frequency doubling perimetry; HFA, Humphrey field analyser; MAP, Medmont automated perimeter; SITA, Swedish Interactive Thresholding Algorithm; SWAP, short wavelength automated perimetry 
Table 1 Description of patients within the study groups

\begin{tabular}{lccll}
\hline Group & Number & Males (\%) & Mean age (SD) & Range \\
\hline Control & 15 & $7(47 \%)$ & 52 years (15 years) & $29-75$ years \\
Glaucoma suspects & 8 & $5(63 \%)$ & 56 years (16 years) & $35-77$ years \\
Ocular hypertension & 8 & $1(13 \%)$ & 60 years (9 years) & $47-74$ years \\
Open angle glaucoma & 32 & $16(50 \%)$ & 64 years (9 years) & $41-79$ years \\
\hline
\end{tabular}

inferiorly, and temporally, and to $30^{\circ}$ nasally. It uses a testing strategy which decreases stimulus intensity by $6 \mathrm{~dB}$ until threshold is crossed and then reverses in steps of $3 \mathrm{~dB}$ until the threshold sensitivity at a particular test location is confirmed..$^{18} 19$

The MAP may be modified to perform flicker perimetry. Targets are presented in a $22^{\circ}$ radius of the central visual field at frequencies varying from $9-18 \mathrm{~Hz}$ (depending on target eccentricity). Target luminance is varied in order to determine threshold. ${ }^{20}$ False positive responses were tested with static stimuli. Flicker perception is thought to be conveyed through the magnocellular (M) pathway. ${ }^{16}$ Being larger in size, ${ }^{21-23} \mathrm{M}$ cells may be lost earlier in glaucoma by means of selective $\operatorname{loss}^{16}$ and, as they only constitute $25 \%$ of ganglion cells, ${ }^{21-23}$ tests which target them, such as flicker perimetry, may be more likely to detect these losses earlier then conventional perimetry because of reduced redundancy. ${ }^{16}$

Frequency doubling perimetry (FDP) uses $10^{\circ}$ square target zones, consisting of alternating vertical white and black stripes (spatial frequency 0.25 cycles per degree, cpd). These stripes are then reversed at a rate of $25 \mathrm{~Hz}$ and the contrast between the stripes is changed to determine sensitivity. The test has been used to detect established visual field losses in the same way that HFA AAP does. ${ }^{24}$ However, recently its ability to detect early visual field losses has been explored..$^{10-12}$

FDP seems to target a subset of the magnocellular pathway with non-linear or Y-like properties (My pathway). ${ }^{16} 25$ This pathway makes up only approximately $15 \%$ of the magnocellular system. ${ }^{26-28}$ As larger cells and relatively few in number, they may be more susceptible to selective loss and reduced redundancy, allowing an earlier detection of any fall in cell numbers. ${ }^{10-1216}$

\section{METHOD}

A total of 63 patients were recruited selectively from a patient population attending an urban glaucoma clinic. None of these had diabetes, cataract, or corneal or retinal disease, which could affect test results. Patients were glaucoma suspects, had ocular hypertension, open angle glaucoma, or were control subjects. The glaucoma suspect group had a family history of glaucoma or had suspicious discs but with no definite structural changes and normal intraocular pressure (IOP $<21$ $\mathrm{mm} \mathrm{Hg}$ ) and visual fields. Ocular hypertension was diagnosed as IOP $\geqslant 21 \mathrm{~mm} \mathrm{Hg}$ on at least three occasions with no previous field changes on full threshold HFA testing and no evidence of glaucomatous optic neuropathy. Open angle glaucoma patients had glaucomatous optic disc changes with or without characteristic visual field abnormality on 24-2 HFA full threshold testing. Among patients with glaucoma, ocular hypertension, or glaucoma suspects, only those patients were included who had at least two consecutive visual fields, performed within the past 2 years. One eye from each patient was considered. When both eyes were eligible a random choice was made.

Medmont, HFA, and FDP were performed in random order after informed consent was obtained. The Humphrey field analyser II (Carl Zeiss, Dublin, CA, USA) was used to perform central 24-2 full threshold, central 24-2 SITA standard and central 24-2 SWAP tests. The determination of a significant
Table 2 Description the amount of visual field loss for patients within the study groups

\begin{tabular}{llll}
\hline \multirow{4}{*}{ Group } & \multicolumn{2}{l}{$\begin{array}{l}\text { Humphrey full } \\
\text { threshold } M D\end{array}$} \\
\cline { 2 - 3 } & Average & (SD) & Range \\
\hline Control & -0.75 & $(1.05)$ & 0.59 to -2.34 \\
Glaucoma suspects & -0.66 & $(1.23)$ & 1.57 to -1.72 \\
Ocular hypertension & -1.19 & $(2.39)$ & 0.90 to -6.41 \\
Open angle glaucoma & -8.20 & $(7.51)$ & 1.04 to -26.58 \\
\hline
\end{tabular}

Table 3 Mean test time (SD) for Humphrey and Medmont perimetry

\begin{tabular}{lll}
\hline & Mean test time & SD \\
\hline Medmont central threshold & 10 minutes & 51 seconds \\
& 51 seconds & \\
Medmont flicker perimetry & 9 minutes & 1 minutes \\
& 47 seconds & 6 seconds \\
Humphrey full threshold & 10 minutes & 1 minutes \\
& 43 seconds & 26 seconds \\
Humphrey SITA & 5 minutes & 1 minutes \\
Short wavelength automated & 44 seconds & 12 seconds \\
perimetry & 35 minutes & 1 minutes \\
Frequency doubling perimetry & 5 minutes & 43 seconds \\
& 8 seconds &
\end{tabular}

scotoma was based on the pattern deviation of the HFA probability plot. Visual field loss was considered significant if it had a pattern typical of glaucoma and occurred in a field with five or more points of $\mathrm{p}<5 \%$, with a cluster of three or more abnormal points of $\mathrm{p}<5 \%$, or two or more points of $\mathrm{p}<1 \%$.

The Medmont M600 automated perimeter (Medmont, Camberwell, Victoria, Australia) was used to perform central 30 degree threshold and 15/22 flicker perimetry. The determination of a significant scotoma was based on the age normal plot of the Medmont M600 printout. Before the analysis, both strict and loose scotoma criteria were developed. For the former, visual field loss was considered significant if it had a pattern typical of glaucoma and occurred in a field with six or more points of $>6 \mathrm{~dB}$ depressed, with a cluster of four or more abnormal points of $>6 \mathrm{~dB}$ depressed, or three or more points of $>18 \mathrm{~dB}$ depressed. For the latter, a scotoma was considered significant if it had a pattern typical of glaucoma and occurred in a cluster of three or more points depressed $>6 \mathrm{~dB}$, or two or more points $>18 \mathrm{~dB}$.

The Humphrey-Zeiss frequency doubling perimeter (Carl Zeiss, Dublin, CA, USA) was used to perform N-30 full threshold testing. Visual field loss was considered significant if there were two or more adjacent zones of $p<5 \%$, or one zone of $p$ $<1 \%$ on the FDP pattern deviation. In all cases, fields were considered reliable if there were less than 33\% false negative and false positive errors and less than $20 \%$ fixation losses.

All patients underwent all five perimetric tests. In order to compare Medmont with other equivalent perimetric methods 
Table 4 Numbers of normal and abnormal Medmont central threshold, Humphrey full threshold, and SITA in the patient sample

\begin{tabular}{|c|c|c|c|c|}
\hline & \multicolumn{2}{|c|}{ Humphrey full threshold } & \multicolumn{2}{|c|}{ Humphrey SITA } \\
\hline & Abnormal & Normal & Abnormal & Normal \\
\hline \multicolumn{5}{|c|}{ Medmont central threshold (strict) } \\
\hline Abnormal & 24 & 2 & 25 & 2 \\
\hline Normal & 1 & 36 & 2 & 34 \\
\hline \multicolumn{5}{|c|}{ Medmont central threshold (loose) } \\
\hline Abnormal & 25 & 9 & 26 & 8 \\
\hline Normal & 0 & 29 & 1 & 28 \\
\hline
\end{tabular}

Table 5 Comparison of Medmont central threshold with Humphrey full threshold and Humphrey SITA showing, kappa statistic, area under the ROC curve (AUC), quadrant analysis, and mean defect correlation

\begin{tabular}{|c|c|c|c|c|}
\hline & \multirow{2}{*}{\multicolumn{2}{|c|}{$\begin{array}{l}\begin{array}{l}\text { Medmont central threshold } \\
\text { (strict) }\end{array} \\
\text { Compared with }\end{array}$}} & \multirow{2}{*}{\multicolumn{2}{|c|}{$\begin{array}{l}\begin{array}{l}\text { Medmont central threshold } \\
\text { (loose) }\end{array} \\
\text { Compared with }\end{array}$}} \\
\hline & & & & \\
\hline & $\begin{array}{l}\text { Humphrey full } \\
\text { threshold }\end{array}$ & $\begin{array}{l}\text { Humphreys } \\
\text { SITA }\end{array}$ & $\begin{array}{l}\text { Humphrey full } \\
\text { threshold }\end{array}$ & Humphrey SITA \\
\hline Kappa statistic & 0.90 & 0.87 & 0.72 & 0.72 \\
\hline AUC & 0.94 & 0.92 & & \\
\hline \multicolumn{5}{|l|}{ Sector correlation ( $r^{2}$ statistic): } \\
\hline Superonasal & $0.86 * *$ & $0.85^{* *}$ & & \\
\hline Superotemporal & 0.80 ** & $0.72 * *$ & & \\
\hline Inferonasal & $0.69 * *$ & $0.62 * *$ & & \\
\hline Inferotemporal & 0.29 ** & $0.23^{* *}$ & & \\
\hline Mean defect correlation ( $r^{2}$ statistic): & $0.89 * *$ & $0.88 * *$ & & \\
\hline
\end{tabular}

Table 6 Numbers of normal and abnormal Medmont flicker perimetry, Humphrey short wavelength perimetry, and Humphrey frequency doubling perimetry in the patient sample

\begin{tabular}{|c|c|c|c|c|}
\hline & \multicolumn{2}{|c|}{$\begin{array}{l}\text { Humphrey short wavelength } \\
\text { perimetry }\end{array}$} & \multicolumn{2}{|c|}{$\begin{array}{l}\text { Humphrey frequency doubling } \\
\text { perimetry }\end{array}$} \\
\hline & Abnormal & Normal & Abnormal & Normal \\
\hline \multicolumn{5}{|c|}{ Medmont flicker (strict) } \\
\hline Abnormal & 23 & 8 & 29 & 2 \\
\hline Normal & 3 & 29 & 2 & 30 \\
\hline \multicolumn{5}{|c|}{ Medmont flicker (loose) } \\
\hline Abnormal & 27 & 10 & 29 & 5 \\
\hline Normal & 2 & 24 & 2 & 27 \\
\hline
\end{tabular}

we compared Medmont central 30 degree threshold perimetry with HFA central 24-2 full threshold and central 24-2 SITA standard. Medmont 15/22 flicker perimetry was compared with HFA central 24-2 SWAP and FDP N-30 full threshold.

The comparisons were multifactorial. To demonstrate the ability of Medmont to localise scotomas in the same areas as the Humphrey perimeter, a quadrant analysis was performed. The abnormal points within each quadrant were totalled and tests were compared with simple linear regression. To illustrate any significance in Medmont's global indices, mean deviations were compared between tests using a simple linear regression. A kappa statistic was calculated to demonstrate the degree of agreement the tests. Finally, an area under the receiver operator curve (ROC) curve was calculated for each pair of tests being compared.

Statistical Analysis System (SAS Institute Inc, Cary, NC, USA) was used for statistical analysis including frequency tables, descriptive statistics, Student's $t$ test and simple linear regression. Excel 97 (Microsoft, Redmond, WA, USA) was used in the calculation of area under the ROC curve and the kappa statistic.

\section{RESULTS}

Consisting of 34 females (54\%) and 29 males (46\%), the average age of the participants was 60 years (standard deviation 13 years). There were 15 controls (24\%), eight glaucoma suspects (13\%), eight ocular hypertensives (13\%), and 32 open angle glaucoma patients $(51 \%)$. A description of these groups and the amount of visual field loss is shown in Tables 1 and 2 respectively. The mean test times for Humphrey and Medmont perimeters are displayed in Table 3.

When Medmont central threshold was compared with HFA full threshold (Tables 4 and 5), a scotoma analysis yielded a kappa statistic of 0.90 under the strict criteria and 0.72 under the loose criteria. The area under the ROC curve was 0.94 , indicating a strong correlation between the two tests (Table 5). 


\begin{tabular}{|c|c|c|c|c|}
\hline & \multicolumn{2}{|l|}{ Medmont flicker (strict) } & \multicolumn{2}{|c|}{ Medmont flicker (loose) } \\
\hline & \multicolumn{2}{|l|}{ Compared with } & \multicolumn{2}{|l|}{ Compared with } \\
\hline & $\begin{array}{l}\text { Humphrey short } \\
\text { wavelength perimetry }\end{array}$ & $\begin{array}{l}\text { Humphrey frequency } \\
\text { doubling perimetry }\end{array}$ & Humphrey SWAP & Humphrey FDP \\
\hline $\begin{array}{l}\text { Kappa statistic } \\
\text { AUC }\end{array}$ & $\begin{array}{l}0.65 \\
0.81\end{array}$ & $\begin{array}{l}0.87 \\
0.96\end{array}$ & 0.62 & 0.78 \\
\hline \multicolumn{5}{|l|}{ Sector correlation ( $r^{2}$ statistic): } \\
\hline Superonasal & $0.48 * *$ & 0.67 ** & & \\
\hline Superotemporal & $0.25^{* *}$ & $0.79 * *$ & & \\
\hline Inferonasal & $0.17^{\star}$ & 0.64 ** & & \\
\hline Inferotemporal & 0.02 & 0.72 ** & & \\
\hline Mean defect correlation ( $r^{2}$ statistic): & $0.57^{* *}$ & $0.79 * *$ & & \\
\hline
\end{tabular}

${ }^{*} p<0.001,{ }^{* *} p<0.0001$.

When Medmont central threshold was compared with HFA SITA standard (Tables 4 and 5), this showed a kappa statistic of 0.87 under the strict criteria and 0.72 under the loose criteria. The area under the ROC curve was 0.92 (Table 5), again indicating a strong correlation. These findings were supported by the quadrant analysis and mean deviation $r^{2}$ statistics, which also show highly significant correlations between Medmont central threshold and HFA full threshold or SITA standard. HFA SITA was significantly faster than Medmont central threshold $(\mathrm{p}<0.001)$, but Medmont central threshold and HFA full threshold had no significant difference in test time $(p=0.53)$.

After Medmont flicker was compared with HFA SWAP (Table 6), this yielded a kappa statistic of 0.65 and 0.62 for the strict and loose criteria respectively. The area under the ROC curve was 0.81 (Table 7). When compared with FDP (Table 6) the kappa statistic was 0.87 and 0.78 for the strict and loose criteria respectively. The area under the ROC curve was 0.96 (Table 7). The $r^{2}$ statistics from the quadrant and mean deviation analysis were also highly significant, although more so for FDP than for SWAP. FDP was significantly faster than Medmont flicker $(p<0.001)$, but Medmont flicker was significantly faster than SWAP $(\mathrm{p}<0.01)$.

\section{DISCUSSION}

The Medmont M600 perimeter, brought out in the late $1980 s^{18}{ }^{18}$ was promoted as quicker than HFA in performing a full threshold analysis of the visual field. ${ }^{18}$ Possibly, recent advances in HFA full threshold analysis have meant that it can be performed in the same time as Medmont. SITA dramatically reduces test time. In this study, Medmont yielded results comparable with those of the HFA and the FDP (Fig 1).

Although Medmont's step size is larger than HFA (6 dB versus $4 \mathrm{~dB}$ ) this has been reported not to cause any difference in accuracy on measuring scotoma size..$^{18}{ }^{19}$ Other Medmont parameters are similar to $\mathrm{HFA}^{18}$ and this is reflected in the high correlation between the two kinds of achromatic perimetry.

A flickering stimulus will target the magnocellular pathway and this has been the basis for many tests of visual field loss, ${ }^{162930}$ the most recent being FDP. Medmont flicker correlates strongly with FDP in all of the parameters tested. As Medmont flicker targets a subgroup of ganglion cells which are felt to be lost early in glaucoma, ${ }^{16}$ it may be detecting visual field losses that may precede detection with achromatic perimetry. Support for this is seen not only in the correlation with FDP but also with SWAP which has the ability to detect scotomas before they become manifest on AAP. ${ }^{8}$ While Medmont flicker cannot be performed as rapidly as FDP, it may be quicker than SWAP.

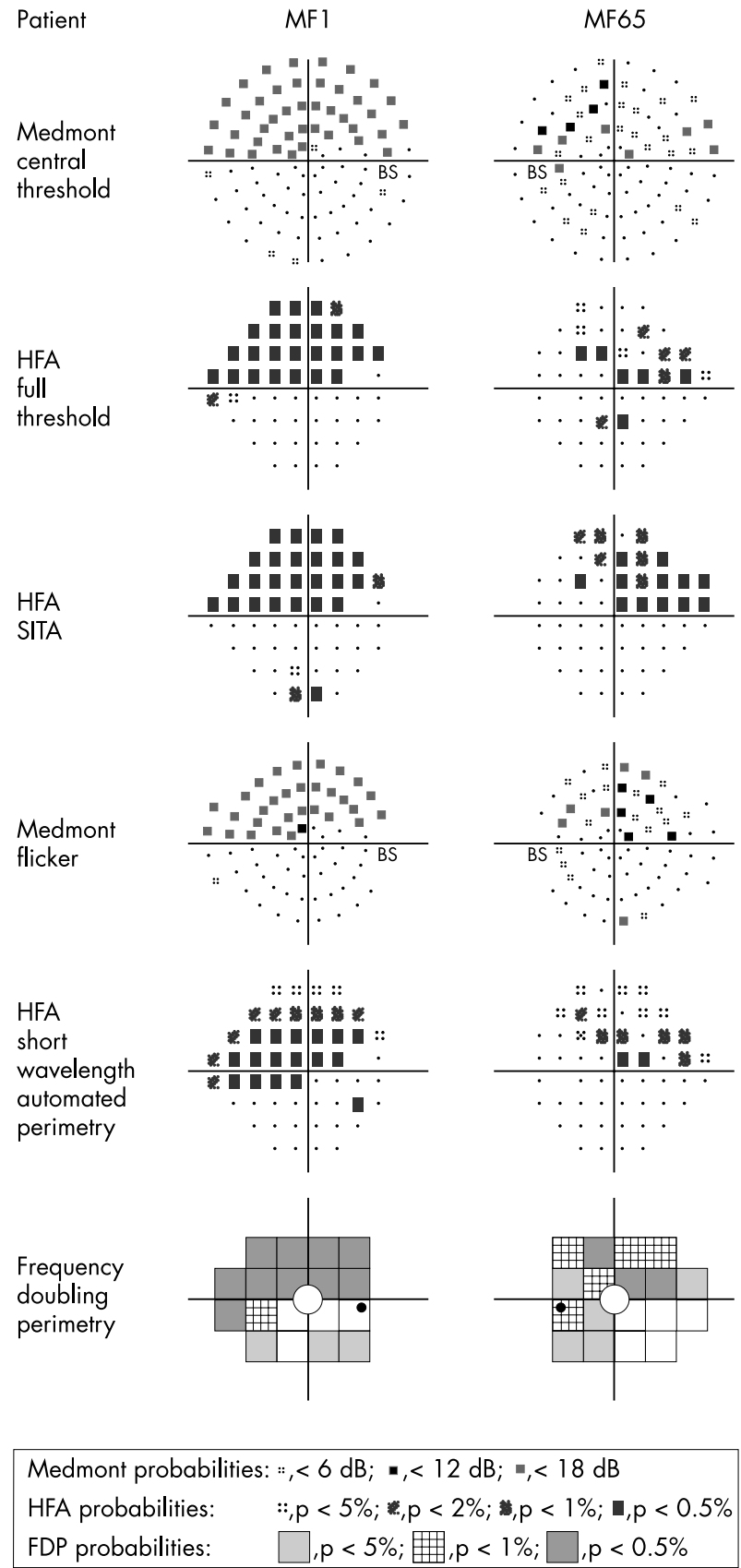

Figure 1 Pattern deviation from two patients (MF1, MF65). 
We conclude that Medmont and Humphrey perimetry correlated favourably with one another, and therefore, both may be used for clinical and research purposes with similar confidence.

\section{ACKNOWLEDGEMENTS}

We would like to thank the staff at Eye Associates for their support and assistance.

\section{Authors' affiliations}

J Landers, A Sharma, I Goldberg, S Graham, Eye Associates, Park House, Macquarie Street, Sydney, Australia

S Graham, Save Sight Institute, Sydney University, Sydney, Australia

Correspondence to: Dr John Landers, Park House, Floor 4, Suite 2 187 Macquarie Street, Sydney, NSW 2000, Australia;

landers@lisp.com.au

Accepted for publication 18 October 2002

\section{REFERENCES}

1 Beck RW, Berstrom TJ, Lichter PR. A clinical comparison of visual field testing with a new automated perimeter, the Humphrey field analyzer, and the Goldmann perimeter. Ophthalmology 1985;92:77-82.

2 Katz J, Quigley HA, Sommer A. Repeatability of the glaucoma hemifield test in automated perimetry. Invest Ophthalmol Vis Sci 1995;36:1658-64

3 McCrary JA, Feigon J. Computerized perimetry in neuro-ophthalmology. Ophthalmology 1979:86:1287-301.

4 Johnson CA, Keltner JL, Balestrery FG. Suprathreshold static perimetry in glaucoma and other optic nerve disease. Ophthalmology 1979;86:1278-86

5 Johnson CA. Role of automation in new instrumentation. Optom Vis Sci 1993;70:288-98.

6 Quigley HA, Addicks EM, Green R. Optic nerve damage in human glaucoma. Arch Ophthalmol 1982;100: 135-46.

7 Harwerth RS, Carter-Dawson L, Shen F, et al. Ganglion cell losses underlying visual field defects from experimental glaucoma. Invest Ophthalmol Vis Sci 1999:40:2242-50.

8 Demirel S, Johnson CA. Short wavelength automated perimetry (SWAP) in ophthalmic practice. J Am Opt Assoc 1996;67:451-6.

9 Johnson CA, Adams AJ, Casson EJ, et al. Blve-on-yellow perimetry can predict the development of glaucomatous visual field loss. Arch Ophthalmol 1993;111:645-50.

10 Johnson CA, Cioffi GA, Van Buskirk EM. Frequency doubling technology perimetry using a 24-2 stimulus presentation pattern. Optom Vis Sci 1999;76:571

11 Brusini P, Busatto P. Frequency doubling perimetry in glaucoma early diagnosis. Acta Ophthalmol (Scand) 1998;227:23-4.
12 Landers J, Goldberg I, Graham S. A comparison of short wavelength automated perimetry with frequency doubling perimetry for the early detection of visual field loss in ocular hypertension. Clin Exp Ophthalmol 2000;28:248-52.

13 Sharma AK, Goldberg I, Graham SL, et al. Comparison of the Humphrey Swedish Interactive Thresholding Algorithm (SITA) and full threshold strategies. J Glaucoma 2000;9:20-7.

14 Bengtsson B, Olsson J, Heijl A, et al. A new generation of algorithms for computerised threshold perimetry, SITA. Acta Ophthalmol (Scand) 1997;75:368-75.

15 Sample PA, Johnson CA, Haegerstrom-Portnoy G, et al. Optimum parameters for short-wavelength automated perimetry. J Glaucoma 1996;5:375-83.

16 Johnson CA. Early losses of visual function in glaucoma. Optom Vis Sci 1995;72:359-70.

17 De Monasterio FM. Asymmetry of on- and off- pathways of blue-sensitive cones of the retina of macaques. Brain Res 1979; 166:39-48

18 Vingrys AJ, Helfrich KA. The Opticom M600: a new LED automated perimeter. Clin Exp Opt 1990;73:3-17.

19 Pye D, Herse P, Nguyen H, et al. Conversion factor for comparison of data from Humphrey and Medmont automated perimeters. Clin Exp Opt 1999;82:11-13.

20 McKendrick AM, Vingrys AJ, Badcock DR, et al. Visual field losses in subjects with migraine headaches. Invest Ophthalmol Vis Sci 2000;41:1239-47.

21 Glovinsky Y, Quigley HA, Dunkelberger GR. Retinal ganglion cell loss is size dependent in experimental glaucoma. Invest Ophthalmol Vis Sci 1991;32:484-91.

22 Chaturvedi N, Hedley-Whyte ET, Dreyer EB. Lateral geniculate nucleus in glaucoma. Am J Ophthalmol 1993;116:182-8.

23 Maddess T, Hemmi JM, James AC. Evidence for spatial aliasing effects in the $y$-like cells of the magnocellular visual pathway. Vis Res 1992; 38: 1843-59.

24 Burnstein Y, Ellish N, Magbalov M, et al. Comparison of frequency doubling perimetry with Humphrey visual field analysis in a glaucoma practice. Am J Ophthalmol 2000;1 129:328-33.

25 Sponsel WE, Argango S, Trigo Y, et al. Clinical classification of glaucomatous visual field loss by frequency doubling perimetry. Am J Ophthalmol 1998;125:830-6.

26 Maddess T, Hemmi JM, James AC. Evidence for spatial aliasing effects in the $y$-like cells of the magnocellular visual pathway. Vis Res 1992; 38: 1843-59.

27 Kaplan E, Shapley RM. X and Y cells in the lateral geniculate nucleus of macaque monkeys. J Physiol 1982;330: 125-43.

28 Maddess T, Henry GH. Performance of nonlinear visual units in ocular hypertension and glaucoma. Clin Vis Sci 1992;7:371-83.

29 Graham SL, Drance SM, Chauhan BC, et al. Comparison of psychophysical and electrophysiological testing in early glaucoma. Invest Ophthalmol Vis Sci 1996;37:2651-62.

30 Casson EJ, Johnson CA, Shapiro LR. Longitudinal comparison of temporal-modulation perimetry with white-on-white and blue-on-yellow perimetry in ocular hypertension and early glaucoma. J Opt Soc Am 1993:10:1792-806. 


\section{LETTERS}

\section{Laser induced chorioretinal venous anastomosis in ischaemic central retinal vein occlusion}

Laser induced chorioretinal venous anastomosis (CRVA) has been advocated by McAllister and Constable as a treatment for non-ischaemic central retinal vein occlusion (CRVO). ${ }^{1}$ This technique potentially offers a means of permanently bypassing the site of obstruction to venous outflow, which is thought to occur in the region of the lamina cribrosa. In ischaemic CRVO, the visual prognosis is usually much poorer, with devastating complications like neovascular glaucoma and progressive macular ischaemia. ${ }^{2}$ In this prospective study, we investigated the feasibility of laser induced CRVA in eyes with ischaemic CRVO, in view of the possibility of avoiding or lessening these severe complications.

\section{Materials and methods}

The classification of ischaemic CRVO was based on the presence of 10 disc diameter or more of capillary non-perfusion in the fundus fluorescence angiography (FFA), according to the criteria in the CRVO study. ${ }^{2}$ Approval from the ethics committee and informed consent from patients were obtained. Inclusion and exclusion criteria are shown in Table 1. All the laser treatment was performed by one of the authors (AK) who had successfully treated patients with non-ischaemic CRVO with a similar procedure. The site for attempts at the creation of anastomosis was in the inferotemporal and superonasal retina over a venous tributary of the retinal vein where it crosses over an underlying choroidal vein, at least 3 disc diameters away from the optic disc Argon or diode laser with $50 \mu \mathrm{m}$ spot size of $0.1-0.2$ second's duration and with a power level of 1.5-2.5 W was focused over the edge of the chosen retinal vein. Increasing power was used until there was haemorrhaging from the vein (Fig lA). The bleeding was stopped by pressure on the eye with a contact lens.

\section{Results}

Six eyes of six patients were included (Table 2 ). All of them had posterior vitreous detachment. Median follow up was 21 months (range 5-31 months). The median preoperative best corrected visual acuity (BCVA) was $3 / 200$ (range, hand movement to $8 / 200$ ). The median postoperative best corrected visual acuity (BCVA) was 2/200 (range, hand movement to 20/200). The median number of attempted anastomosis sites per eye was four (range, two to four). Through repeated ophthalmoscopic examination, FFA, and indocyanine green angiography, no functional anastomosis was found. A small nodular fibrotic scar was noted in each site (Fig 1B). No other significant laser related complication was found. One eye eventually developed rubeotic glaucoma

\section{Comment}

In non-ischaemic CRVO, a successful CRVA was created in $33-54 \%$ of eyes. ${ }^{13}$ Laser

Table 1 Inclusion and exclusion criteria of patients

Inclusion criteria:
1 Confirmed presence of central retinal vein occlusion
2 Central retinal vein occlusion $\leqslant 3$ months' duration
3 Visual acuity $</=20 / 200$
4 Intraocular pressure $<30 \mathrm{~mm} \mathrm{Hg}$
5 Ability to obtain good quality fundus photographs and angiograms
6 Age $\geqslant 21$ years old
Exclusion criteria:
1 Intercurrent eye disease of study eye that is likely to affect visual acuity over study period
2 Presence of any diabetic retinopathy in either eye
3 New or old branch artery/vein occlusion in study eye
4 Other retinal vascular disease in study eye
5 Vitreous haemorrhage other than breakthrough in study eye
6 Presence of neovascularisation of the study eye (iris, angle, retina, disc)
7 Heparin/warfarin sodium cannot be discontinued for duration of study
8 Impossible to differentiate between ischaemic and non-ischaemic central retinal vein occlusion
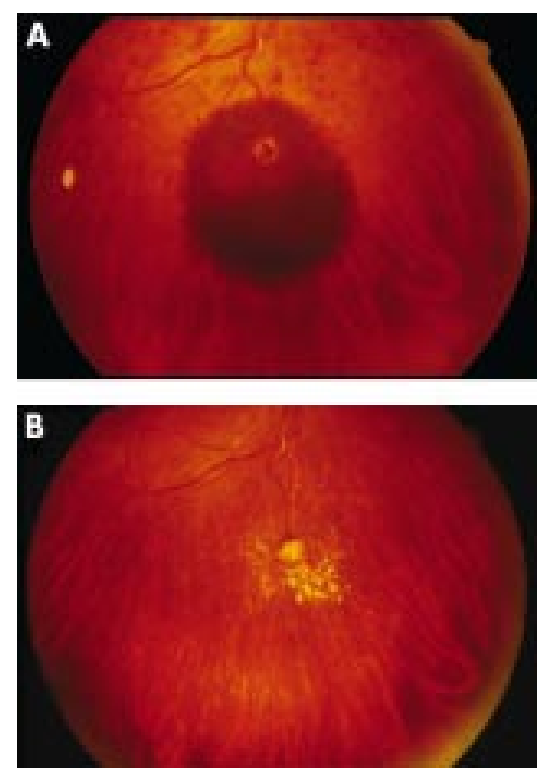

Figure 1 Patient 3. (A) Retinal and subretinal haemorrhage around the attempted anastomotic site along the inferotemporal retinal vein shortly after the laser treatment. (B) Seven months later, a small fibrotic nodule was present with minimal amount of altered blood.

photocoagulation treatment parameters differed, because the superiority of one combination of parameters compared with another had not been demonstrated. ${ }^{3}$ In our study, it appears that argon or diode laser induced CRVA was not feasible in ischaemic CRVO. We attribute this to the severe endothelial cell damage secondary to ischaemia and venous thrombosis across the retinal circulation. In a dog model without retinal vein occlusion, a successful laser induced CRVA was shown to be lined by endothelial cells. ${ }^{4}$ Despite the failure to create functional CRVA, we did not encounter any adverse complication related to the laser treatment. The presence of posterior vitreous detachment in our patients might have lessened the chance of development of chorioretinovitreal neovascularisation. Successful CRVA in ischaemic CRVO has been reported to be established through pars plana vitrectomy with direct surgical puncture or erbium:YAG laser. ${ }^{5-7}$ This surgical approach may be a better option to create CRVA in ischaemic eyes, especially when the posterior hyaloid is still attached preoperatively.

Table 2 Baseline and outcome characteristics of patients receiving laser treatment

\begin{tabular}{|c|c|c|c|c|c|c|c|c|c|}
\hline $\begin{array}{l}\text { Patient } \\
\text { No }\end{array}$ & Sex/age & $\begin{array}{l}\text { Interval of CRVO } \\
\text { and laser (weeks) }\end{array}$ & $\begin{array}{l}\text { Laser } \\
\text { used }\end{array}$ & $\begin{array}{l}\text { No of laser } \\
\text { sessions }\end{array}$ & $\begin{array}{l}\text { Total No of laser } \\
\text { sites attempted }\end{array}$ & $\begin{array}{l}\text { Initial } \\
\text { BCVA }\end{array}$ & $\begin{array}{l}\text { Final } \\
\text { BCVA }\end{array}$ & $\begin{array}{l}\text { Duration of follow } \\
\text { up (months) }\end{array}$ & Complication \\
\hline 1 & $M / 79$ & 5 & Argon & 2 & 4 & $8 / 200$ & $H M$ & 31 & Neovascular glaucoma \\
\hline 2 & $\mathrm{~F} / 80$ & 2 & Diode & 1 & 2 & $2 / 200$ & $2 / 200$ & 31 & \\
\hline 3 & $F / 54$ & 3 & Argon & 2 & 4 & $4 / 200$ & $20 / 200$ & 19 & \\
\hline 4 & $M / 53$ & 12 & Diode & 2 & 4 & $8 / 200$ & $5 / 200$ & 23 & \\
\hline 5 & $\mathrm{~F} / 80$ & 6 & Argon & 2 & 4 & $H M$ & $H M$ & 7 & \\
\hline 6 & $F / 78$ & 10 & Argon & 1 & 2 & $H M$ & $2 / 200$ & 5 & \\
\hline
\end{tabular}

CRVO = central retinal vein occlusion; $B C V A=$ best corrected visual acuity . 
Financial and proprietary interest: nil.

Financial support: nil.

A K H Kwok

Department of Ophthalmology, Hong Kong Sanatorium and Hospital, Hong Kong, People's Republic of China

A K H Kwok, V Y W Lee, T Y Y Lai

Department of Ophthalmology and Visual Sciences, The Chinese University of Hong Kong, Hong Kong Eye Hospital, Hong Kong, People's Republic of China

C Hon

Department of Ophthalmology, Queen Mary Hospital, Hong Kong, People's Republic of China

Correspondence to: Dr Alvin K H Kwok Department of Ophthalmology, Hong Kong Sanatorium and Hospital, 2 Village Road, Happy

Valley, Hong Kong; alvinkwok@hksh.com

Accepted for publication 1 December 2002

\section{References}

1 McAllister IL, Constable IJ. Laser-induced chorioretinal venous anastomosis for non-ischemic central retinal vein occlusion: evaluation of the complications and their risk

factors. Am J Ophthalmol 1998; 126:219-29.

2 Central Vein Occlusion Study Group.

Baseline and early natural history report: the central vein occlusion study. Arch Ophthalmol 1993;111:1087-95.

3 Fekrat S, Goldberg MF, Finkelstein D. Laser-induced chorioretinal venous anastomosis for nonischemic central or branch retinal vein occlusion. Arch Ophthalmol 1998; 11 16:43-52.

4 Vijayasekaran S, Yu DY, McAllister IL, et al. Optimal conditions required for the creation of an iatrogenic chorioretinal venous anastomosis in the dog using argon green laser photocoagulation. Curr Eye Res $1995 ; 14: 63-70$

5 Fekrat S, de Juan E. Chorioretinal venous anastomosis for central retinal vein occlusion: transvitreal venipuncture. Ophthalmic Surg Lasers 1999;30:53-5.

6 Peyman GA, Kishore K, Conway MD. Surgical chorioretinal venous anastomosis for ischemic central retinal vein occlusion. Ophthalmic Surg Lasers 1999;30:605-14.

7 Quiroz-Mercado H, Sanchez-Buenfil E, Guerrero-Naranjo JL, et al. Successful erbium: YAG laser-induced chorioretinal venous anastomosis for the management of ischemic central retinal vein occlusion. A report of two cases. Graefes Arch Clin Exp Ophthalmol 2001;239:872-5.

\section{Actinic granuloma of the conjunctiva}

Actinic granuloma is a condition characterised, histologically, by a preponderance of giant cells in close relation with damaged elastic fibres and the absence of necrobiosis, lipid, mucin, and palisading of the granuloma. ${ }^{1}$ The term was coined in 1975 by

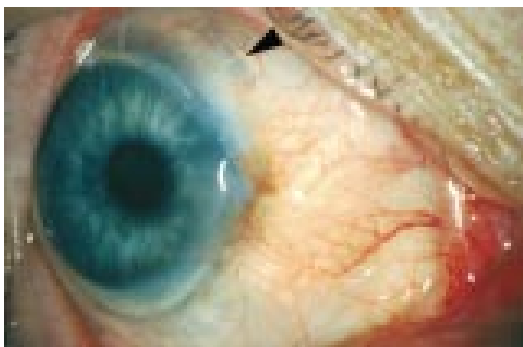

Figure 1 Presenting appearance of lesion scleral thinning shown by arrowhead.

O'Brien who described similar histological features in cutaneous lesions of patients with sun damaged skin. ${ }^{2}$ Actinic elastosis is the hallmark of pingueculae and has been noted in association with a granulomatous reaction in only one previous report.

Over the past three decades, three cases of actinic granuloma of the conjunctiva have been documented in the literature (Table 1). . $^{4-6}$

The paucity of reports ensures that the condition is under-recognised both clinically and pathologically. We describe a further case with the novel association of scleral thinning, and further review the literature with reference to pathogenesis, disease associations, treatment, and significance for both ophthalmologists and pathologists.

\section{Case history}

A 67 year old white woman presented to the ophthalmology department with a 3 week history of a painless, red right eye. She had no previous ophthalmic problems. Significant past medical history included treated pulmonary tuberculosis and a lumpectomy for breast carcinoma 10 years previously. She had no significant family history and otherwise was generally well.

Ocular examination demonstrated a $3 \times 3$ $\mathrm{mm}$, raised, flesh coloured, vascularised lesion on the right nasal bulbar conjunctiva with an associated corneal dellen (Fig 1). Further scleral changes were observed circumferentially around the limbus under an apparently healthy conjunctiva (Fig l, arrowhead).

Initial differential diagnosis was carcinoma in situ of the conjunctiva or metastasis from breast carcinoma, although the lesion was not clinically typical of either.

An excision biopsy was performed. During surgery the underlying sclera was noted to be degenerate with significant thinning.

Histology of the lesion demonstrated dysplasia within the squamous epithelium and prominent solar elastosis with a granulomatous response to degenerative elastic fibres There was a lymphoplasmacytic infiltrate characteristic of an inflamed pinguecula with

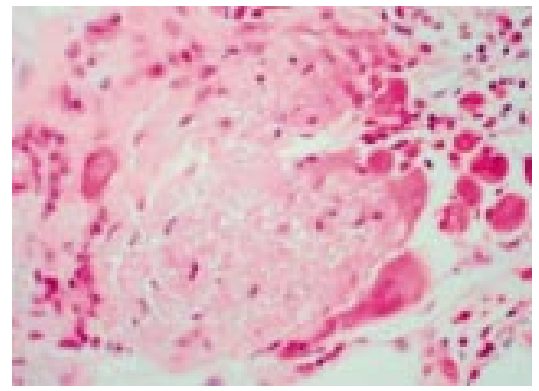

Figure 2 Histology of excised lesion.

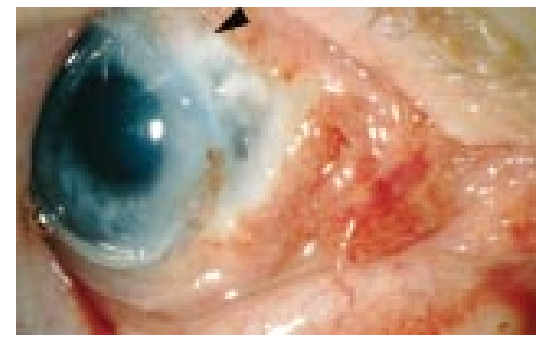

Figure 3 Appearance post-incision Persisting scleral thinning shown by arrowhead.

granulomatous features suggestive of actinic granuloma (Fig 2).

Investigations into the cause of the underlying focal scleral atrophy included full blood count, erythrocyte sedimentation rate, serum VDRL, serum complement, anti-ro and anti-la antibodies, and rheumatoid factor which were all within normal limits. A screening serum ANCA was weakly positive (1:20) but antimyeloperoxidase assays were negative.

Anterior segment ultrasonography was normal. Fluorescein angiography of the anterior segment demonstrated an evenly perfused iris, but a filling defect clearly delineated the atrophy and thinning at the lesion site. Our patient was subsequently treated with topical antibiotics and eye padding and responded favourably over several weeks with progressive epithelialisation over the excision defect (Fig 3). The scleral changes persisted after resolution of the epithelial defect (Fig 3, arrowhead).

\section{Comment}

$\mathrm{O}^{\prime}$ Brien, in his original description of actinic granuloma, described the pathogenesis as a phenomenon of repair occurring in damaged connective tissue. ${ }^{2}$ This concept was disputed by Ragaz and Ackerman ${ }^{7}$ who believed that the granulomatous inflammation was not a response to degenerative elastotic fibres but

Table 1 Review of previously published cases of actinic granuloma

\begin{tabular}{|c|c|c|c|c|c|c|}
\hline & $\begin{array}{l}\text { Patient age } \\
\text { (years) }\end{array}$ & Sex & Location & $\begin{array}{l}\text { Size of } \\
\text { lesion }\end{array}$ & Clinical presentation & Differential diagnosis \\
\hline Case 1, Proia et $a l^{4}$ & 38 & Female & Temporal bulbar conjunctiva & $2 \mathrm{~mm}$ & $\begin{array}{l}3 / 52 \text { History of painless } \\
\text { red eye }\end{array}$ & Vascularised pinguecula \\
\hline Case 2, Ferry et a ${ }^{5}$ & 30 & Female & Temporal bulbar conjunctiva & $2 \times 3 \mathrm{~mm}$ & $6 / 52$ History of red eye & $\begin{array}{l}\text { Pingueculitis, contact lens reaction, } \\
\text { conjunctival naevus }\end{array}$ \\
\hline Case 3, Steffen et al ${ }^{k}$ & 39 & Female & Conjunctiva, site unknown & Not known & Not known & Pingueculitis, Bowen's disease \\
\hline Case 4, Gallagher et al & 67 & Female & Nasal bulbar conjunctiva & $3 \times 3 \mathrm{~mm}$ & $\begin{array}{l}3 / 52 \text { History of painless } \\
\text { red eye }\end{array}$ & $\begin{array}{l}\text { Bowen's disease, breast } \\
\text { metastasis }\end{array}$ \\
\hline
\end{tabular}


that the lesions described by O'Brien represented variants of granuloma annulare, a disorder of skin and ocular adnexae. ${ }^{89}$ The existence of conjunctival actinic granulomas in isolation distinguishes this condition from granuloma annulare and implies that granuloma formation can occur in response to elastotic material. Furthermore, actinic granulomas are histologically distinct with prominent elastotic degeneration of connective tissue fibres, giant cells, and inconspicuous palisading of epithelioid histiocytes.

McGrae postulated that actinic granuloma represented a cell mediated immune response to weakly antigenic determinants on actinically altered elastotic fibres with a predominance of helper $\mathrm{T}$ cells in the lymphocytic infiltrate.

More recently the association of temporal arteritis and actinic granulomas of the skin has been documented. ${ }^{10}$ It is hypothesised that actinic radiation selectively injures elastic tissue in the skin and its superficial arteries and this tissue may then become antigenic, with local, humoral, and systemic overtones.

It is reported that the serum of patients with untreated giant cell arteritis contains a significantly elevated level of an elastase in the form of matrix metalloproteinase 9 (MMP-9) and that this enzyme was found to be abundant in the vicinity of damaged temporal internal elastic laminae. ${ }^{11}$ Gillot $e t$ $a l^{12}$ observed that sera from 12 of 13 patients with untreated giant cell arteritis contained high levels of elastase derived elastin peptides and that the peptides were targeted by T lymphocytes such as appear in the actual lesions of actinic granuloma and giant cell arteritis. ${ }^{13}$ This mode of autoimmune reaction complies with the "danger" model of autoimmunity described by Matzinger and appraised by Larkin. ${ }^{14}$

Our case presented with the novel association of an underlying focal scleral atrophy. Negative investigations for scleritis would suggest that this feature may be an extension of the autoimmune process representative of actinic granuloma rather than an independent idiopathic scleritis.

It is interesting to note that all documented cases of actinic granuloma of the conjunctiva have occurred in females which would be supportive of an autoimmune pathogenesis. Clinically, the differential diagnosis of conjunctival actinic granuloma includes pingueculitis, Bowen's disease, conjunctival naevus, granuloma annulare (pseudorheumatoid nodule), and episcleral rheumatoid nodule.

Pathologically, the differential diagnosis includes pingueculae, pingueculitis, infection-particularly fungal, parasitic, or mycobacterial-and foreign body reactions. However, there is no granulomatous reaction to the actinic elastosis in pingueculae. In fungal and parasitic lesions there is often a prominent eosinophilic infiltrate associated with the granulomas. Caseous necrosis is seen in mycobacterial infections. In difficult cases special stains may help. Polarised light microscopy rules out the presence of any birefringent material.

Actinic granuloma of the conjunctiva represents a distinct clinical, histopathological, and immunological entity. Its classic presentation over a short period of a few weeks and poor response to topical steroid treatment should aid the ophthalmologist in recognising this lesion. Of practical importance to the ophthalmic pathologist is recognition that the granulomatous inflammation may be associated with elastotic degenera- tion and does not necessarily imply the presence of a foreign body, fungal, or mycobacterial infection

\section{J Gallagher, F Roberts, S Osborne,} C M Kirkness

Tennent Institute of Ophthalmology, Gartnave General Hospital, Great Western Road, Glasgow

G12 OYN, UK

Correspondence to: Stuart A Osborne, Tennent Institute of Ophthalmology, Gartnavel General Hospital, Great Western Road, Glasgow G12 OYN, UK; stozzie@hotmail.com

Accepted for publication 9 December 2002

\section{References}

1 McGrae JD Jr. Actinic granuloma: a clinical, histopathologic, and immunocytochemical study. Arch Dermatol 1986;122:43-7.

2 O'Brien JP. Actinic granuloma: an annular connective tissue disorder affecting sun- and 1975;111:460-6.

3 Bernardino V, Olivar E, Mangubat L, et al. Solitary nodular conjunctivitis-the inflamed pinguecula, granulomatous reaction to elastotic fibres. Philippine J Ophthalmol 1972;4:1

4 Proia AD, Browning DJ, Klintworth GK. Actinic granuloma of the conjunctiva. Am J Ophthalmol 1983;96:1 16-18.

5 Ferry AP, Kaltreider SA, Wyatt DB. Actinic granuloma of the conjunctiva. Arch Ophthalmol 1984;102:1200-2

6 Steffen C. Actinic granuloma of the conjunctiva. Am J Dermatopathol 1992;14:253-4

7 Ragaz A, Ackerman AB. Is actinic granuloma a specific condition? Am J Dermatopathol 1979; 1:43-50

8 Rao NA, Font RL. Pseudorheumatoid nodules of the ocular adnexae. Am J Ophthalmol 1975;79:471-8.

9 Ferry AP. Subcutaneous granuloma annulare ("pseudorheumatoid nodule") of the eyebrow. J Pediatr Ophthalmol 1997; 14:154-7. heat-damaged (elastotic) skin. Arch Dermatol
10 O'Brien JP, Regan W. Actinically degenerate elastic tissue is the likely antigenic basis of actinic granuloma of the skin and of temporal arteritis. J Am Acad Dermatol 1999;40:214-22.

11 Sorbi D, French DL, Nuovo GJ. Elevated levels of 92-kd type IV collagenase (matrix metalloproteinase 9) in giant cell arteritis. Arthritis Rheum 1996;39:1747-53.

12 Gillot J-M,Masy E, Davril M. Elastase derived elastin peptides: putative autoimmune targets in giant cell arteritis. J Rheumatol 1997;24:677-82.

13 Andersson R. Immunological studies in giant cell arteritis. Ballieres Clin Rheumatol 1991;5:405-12.

14 Larkin M. Polly Matzinger: immunology's dangerous thinker. Lancet 1 197;350:38.

\section{Unilateral nasal hemianopsia secondary to posterior subcapsular cataract}

Visual field defects respecting the vertical midline are a common occurrence associated with focal neurological lesions. However, unilateral nasal hemianopsias are rare defects, documented to be associated with pituitary adenomas, temporal optic nerve lesions, and suprasellar aneurysms. ${ }^{1}$ Cataracts are known to depress the overall sensitivity of the visual field, ${ }^{23}$ but localised visual field defects due to cataract are extremely rare and, to our knowledge, only three other cases have been reported in the literature. ${ }^{4-6}$ We report a case of a right unilateral nasal hemianopsia resulting from central posterior subcapsular lens opacity.

\section{Case report}

A 51 year old woman treated for normal tension glaucoma in her right eye for 2 years attended for a review of her glaucoma following a change of medication with the addition of bimonidine eye drops to dorzolamide eye drops. At this 3 monthly review the patient
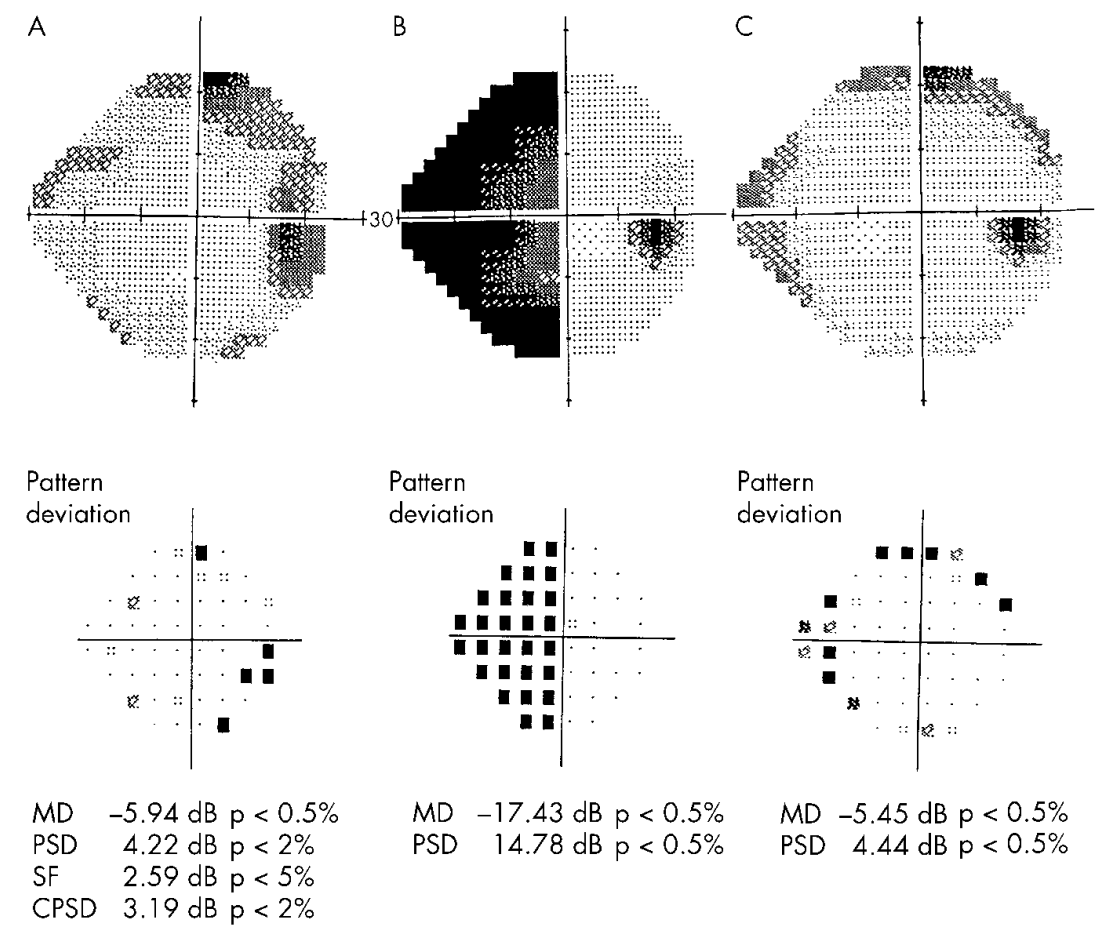

MD $-17.43 \mathrm{~dB} p<0.5 \%$
PSD $14.78 \mathrm{~dB} p<0.5 \%$

MD $-5.45 \mathrm{~dB} p<0.5 \%$

PSD $\quad 4.22 \mathrm{~dB} p<2 \%$

CPSD $3.19 \mathrm{~dB} p<2 \%$

Figure 1 Humphrey 24-2 visual field showing (A) precataract visual field, (B) field with cataract and visual field defect, $(C)$ visual field after cataract removal. 
gave a 1 month history of a sudden onset of misty vision affecting her right nasal visual field noticed while driving her car. There were no other associated neurological symptoms. Just before this she had been diagnosed with "borderline" systemic hypertension. There were no other risk factors for a vascular event, although there is a positive family historyher father had had a cerebrovascular accident.

On examination, her visual acuity had deteriorated from $6 / 6$ to $6 / 24$ in the right eye, remaining unchanged at $6 / 6$ in the left since the previous visit. It had also been documented that letters on the nasal side of the Snellen chart were not seen with the right eye. Confrontation visual field demonstrated a nasal hemianopsia of the right eye. Her pupils were equal with normal reactions to light and accommodation. Dilated slit lamp biomicroscopy revealed marked central posterior subcapsular lens opacity with very mild subcapsular changes in the other eye, previously documented as normal. Retinal examination was normal and the optic discs pathologically cupped with inferior rim thinning; changes consistent with glaucoma, although there were no documented changes from the previous visit 6 months earlier.

Further neurological and cardiovascular examination, other than a blood pressure of 170/70 mm Hg, were also unremarkable.

The right nasal hemianopsia respecting the vertical midline was confirmed on a clinically reliable Humphrey 24-2 plot with a change in mean deviation from -5.94 to -17.43 from the previously documented visual field (see Fig 1). The visual field of the left eye was normal. Routine blood tests and chest $x$ ray were normal. A computed tomograph (CT) scan of the brain, orbits and visual pathways was also unremarkable. In the absence of a focal neurological lesion this woman subsequently underwent an uncomplicated right phacoemulsification and intraocular lens replacement. A repeat red spot visual field revealed complete reversal of the previously documented right nasal hemianopsia, and a restoration of the visual acuity to $6 / 6$.

\section{Comment}

Media opacities are known to cause visual field defects, ${ }^{7}$ the degree of which varies from generalised depression of the visual field ${ }^{8}$ to apparent scotomatous areas. Localised paraxial lens opacities causing defects mimicking neurological abnormalities are extremely rare. These opacities necessitate a posterior position in the lens to produce a relative scotoma. An opacity in the media anteriorly placed produce generalised reduction in the visual field. In the previous three reported cases all the cataracts were posterior subcapsular in nature.

Our case is unusual in that the cataract was placed centrally, not temporally as may be expected with a nasal defect. Further, the history suggested a sudden onset which necessitated neurological examination and investigation.

We feel it would have been inappropriate to proceed to surgical intervention without previous investigation, which should always include a CT scan (more preferably, if readily available, an magnetic resonance imaging (MRI) scan), of the optic nerves and visual pathways. This unusual visual field defect may have been present for some time before the appearance of the cataract but, if subtle, may not have been evident. However, the presence of the cataract may have decreased the sensitivity of the eye and made the visual defect more prominent. Our concern with this woman was that removing the cataract may have disguised a more sinister underlying pathology - that is, a neurological defect, so we decided on a red spot visual field to confirm that such a defect was indeed not present.

Whereas in this case the right nasal hemianopsia was due to a posterior subcapsular cataract, we believe that a neurological cause for the field defect should always be sought, particularly with a history of sudden onset. Cataract extraction should be considered only establishing the absence of the same. Further, consider performing a postoperative red spot visual field test to confirm the absence of focal neurology in such eyes.

I Rahman, A Nambiar, A F Spencer Manchester Royal Eye Hospital, Lister Centre, Nelson Street, Manchester, UK

Correspondence to: Mr Imran Rahman, Manchester Royal Eye Hospital, Lister Centre, Nelson Street, Manchester, UK; imran1973@tiscali.co.uk

Accepted for publication 9 December 2002

\section{References}

1 Miller NR, Newman NJ. Topical diagnosis of lesions in the visual sensory pathway. In: Miller NR, Newman NJ, eds. Walsh and Hoyt's clinical neuro-ophthalmolgy. 5th ed. Baltimore: Williams and Wilkins,

1998;1:302-3

2 Fine EM, Rubin GS. Effects of cataract and scotoma on visual acuity: a simulation study. Optom Vis Sci 1999:76:468-73.

3 Fine EM, Rubin GS. The effects of simulated cataract on reading with normal vision and simulated central scotoma. Vis Res 1999;39:4274-85.

4 Karp CL, Fazio JR. Traumatic cataract presenting with unilateral nasal hemianopsia. J Cataract Refract Surg 1999;25:1302-3.

5 Phillips CI, Vaid RL, Adams AD. Field defect due to posterior cortical paraxial lens opacity. A Case Report. Trans Ophthalmol Soc UK 1978;98:486-9.

6 Lyne AJ, Phillips Cl. Visual field defects due to opacities in the optical media. $\mathrm{BrJ}$ Ophthalmol 1969;53:1 19-22

7 Hayashi K, Hayashi H, Nakao F, et al. Influence of cataract surgery on automated perimetry in patients with glaucoma. Am J Ophthalmol 2001;132:41-6

8 Lam BL, Alward WLM, Kolder HE. Effect of cataract on automated perimetry. Ophthalmology 1991;98:1066-70.

\section{Lack of human papillomavirus in} pterygium of Chinese patients

\section{from Taiwan}

We read with interest that Gallagher et al had demonstrated the association of human papillomavirus (HPV) and pterygium by polymerase chain reaction (PCR). ${ }^{1}$ Several hypotheses concerning the pathogenesis of pterygia have been proposed, including exposure to ultraviolet irradiation ${ }^{2}$ and other environmental factors, genetic predisposition, and viral infections. ${ }^{3}$ The various theories regarding pterygium formation imply that much about the pathogenesis of pterygia remains to be investigated.

The involvement of HPV in the genesis of pterygia is controversial. Some authors have demonstrated that HPV is present in $24-50 \%$ of specimens, whereas others have failed to detect HPV in pterygia. ${ }^{4-7}$ To help resolve this dilemma, we evaluated 65 pterygia, 23 pinguecula, and 88 normal conjunctiva derived from Chinese patients in Taiwan for the presence of HPV DNA. We used PCR with three different consensus primer sets-MY09/ MYll (MY), L1C1/LlC2-1 (LC), and GP5/GP (GP).

\section{Material and methods}

Samples were obtained from consecutive patients treated at the ophthalmological clinic of the Taipei Veterans General Hospital. Medical and ophthalmologic histories were recorded for each patient, a slit lamp microscope examination was performed, and pterygia were photographed before surgery. In each case, a specimen of adjacent clinically normal conjunctival tissue (from the 12 o'clock position of the corneoconjunctival limbus) was obtained. Immediately after surgery, tissue specimens (pterygia, pingueculas, or conjunctival tissues) were stored at $-70^{\circ} \mathrm{C}$.

\section{DNA preparation}

The DNA from specimens was isolated as described previously. ${ }^{8}$ Briefly, the lysis buffer ( 10 mM TRIS-HCl; pH 7.5, 1 mM EDTA, pH $7.9 ; 0.5 \%$ SDS ) and the proteinase $\mathrm{K}$ ( 100 $\mu \mathrm{g} / \mathrm{ml}$ ) were added to the specimens and incubated overnight at $37^{\circ} \mathrm{C}$. The standard phenol-chloroform extraction and the ethanol precipitation were used for DNA purification and the pelleted DNA was resuspended in 50-100 $\mu \mathrm{l}$ of tridistillated sterile water. To determine the quality and quantity of the isolated DNA, each pelleted DNA sample was analysed by electrophoresis on $1 \%$ agarose gels stained with ethidium bromide and viewed spectrophotometrically.

\section{PCR analysis for HPV}

Each amplification reaction was carried out in a total volume of $20 \mu$ l overlaid with one drop of mineral oil and contained $10 \mathrm{mM}$ TRIS-HCl $(\mathrm{pH} 8.3), 50 \mathrm{mM} \mathrm{KCl}, 0.25 \mathrm{U}$ Taq DNApolymerase (Perkin-Elmer), and 100-200 ng DNA. The concentration of dNTPs and $\mathrm{MgCl}_{2}$ varied with each set of primers. Each PCR was carried out in DNA thermal cycler (Perkin-Elmer CETUS DNA Thermal Cycler 480) with the first denaturation step at $92^{\circ} \mathrm{C}$ for 4 minutes and the final extension step at $72^{\circ} \mathrm{C}$ for 15 minutes. The conditions and the number of denaturation-annealingextraction cycles were different with each set of primers.
Table 1 Consensus primer sequences for human papillomavirus DNA detection

\begin{tabular}{|c|c|}
\hline Primer & Sequence* $\left(5^{\prime}-3^{\prime}\right)$ \\
\hline MY11 & GCMCAGGGWCATAAYAATGG \\
\hline MYO9 & CGTCCMARRGGAWACTGATC \\
\hline $\mathrm{LICl}$ & CGTAAACGTTTTCCCTATTTTTTT \\
\hline LIC2-1 & TACCCTAAATACTCTGTATTG \\
\hline GP5 & TTTGTTACTGTGGTAGATAC \\
\hline GP6 & GAAAAATAAACTGTAAATCA \\
\hline
\end{tabular}

${ }^{*} M=A+C, R=A+G, W=A+T, Y=C+T$. 
Table 2 Characteristics of patients with pterygia and pinguecula

\begin{tabular}{lll}
\hline & Pterygium & Pinguecula \\
\hline Patients (M/F) & $65(40 / 25)$ & $23(15 / 8)$ \\
Age (years, mean (SE)) & $63.3(5.9)$ (range 55.5-82.3) & $58.3(7.4)$ (range \\
& & $44.4-71.2)$ \\
Medication for conjunctivitis (\%) & $20(30.8)$ & $3(13.0)$ \\
Duration of lesion (years, mean (SE)) & $9.8(3.7)$ (range 5.5-21.5) & $18.1(7.9)$ (range \\
Conjunctivitis history (\%) & $24(36.9)$ & $10.0-28.5)$ \\
\hline
\end{tabular}

To control the quality of the isolated DNA internally, the $268 \mathrm{bp}$ sequence of $\beta$ globulin gene was amplified using PC04 (5'CAACTTCATCCACGTTCACC3') primers and GH20 (5'GAAGAGCCAAGGACAGGTAC3 $^{\prime}$ ) primers ${ }^{9}$ in the multiplex PCR with the MY, LC, or GP primers. DNA samples extracted from cell cultures infected with HPV were used as a positive control. Each PCR product was analysed by electrophoresis on $2 \%$ agarose gels stained with ethidium bromide.

PCR with MYO9 and MY1 1 consensus primers

The PCR with MY09/MYll was performed as described previously. ${ }^{10}$ The PCR methods with the three different sets of primers were described previously. ${ }^{11}$ The PCR mixture was complemented with $2.5 \mathrm{mM} \mathrm{MgCl}_{2}, 0.1 \mathrm{mM}$ of each dNTP, $0.5 \mu \mathrm{M}$ MY09 and MY11 primers (Table 1) and $0.3 \mu \mathrm{M}$ PC04 and GH 20 primers. The DNA amplication was carried out during 30 cycles that included denaturation at $92^{\circ} \mathrm{C}$ for 30 seconds, annealing at $53^{\circ} \mathrm{C}$ for 30 seconds, and primer extension at $72^{\circ} \mathrm{C}$ for 30 seconds.

PCR with $\mathrm{L} 1 \mathrm{C} 1, \mathrm{~L} 1 \mathrm{C} 2-1$ consensus primers The PCR with LlC1/LlC2-1 was performed as described previously. ${ }^{10}$ The PCR mixture was complemented with $4 \mathrm{mM} \mathrm{MgCl}_{2}, 0.2 \mathrm{mM}$ of each dNTP, $0.5 \mu \mathrm{M} \mathrm{LICl}$, and $0.25 \mu \mathrm{M} \mathrm{L1C1-1}$ primers (Table 1). The DNA amplication was carried out during 30 cycles that included denaturation at $92^{\circ} \mathrm{C}$ for 30 seconds, annealing at $53^{\circ} \mathrm{C}$ for 30 seconds, and primer extension at $72^{\circ} \mathrm{C}$ for 30 seconds.

PCR with GP5, GP6 consensus primers The PCR with GP5/GP6 was performed as described previously. ${ }^{10}$ The PCR mixture was complemented with $2.5 \mathrm{mM} \mathrm{MgCl}_{2}, 0.05 \mathrm{mM}$ of each dNTP, $0.5 \mu \mathrm{M}$ GP5 and GP6 primers (Table 1) and $0.3 \mu \mathrm{M}$ PC04 and GH 20 primers. The DNA amplication was carried out during 40 cycles that included denaturation at $94^{\circ} \mathrm{C}$ for 30 seconds, annealing at $45^{\circ} \mathrm{C}$ for 30 seconds, and primer extension at $72^{\circ} \mathrm{C}$ for 30 seconds.

\section{Results}

The specimens included 65 conjunctival pterygia, 23 pingueculas, and 88 normal conjunctivas. Characteristics of patients are shown in Table 2. We were unable to detect any HPV DNA fragments in the 23 specimens of pingueculae, 65 specimens of pterygia, and 88 specimens of normal conjunctiva tested.

\section{Comment}

It has been proved that HPV possesses oncogenic potential and contributes to the development of various preneoplastic and neoplastic conditions. ${ }^{12}$ DNA of many types of HPV, particularly types 16 and 18 , has been detected in papillomas, dysplasia, and cancers observed on the eyelids, lacrimal outflow tract, conjunctiva, and cornea. ${ }^{13}{ }^{14}$ In this study, three sets of consensus primers, MY, LC, and GP, were used; we were unable to detect HPV in any pterygium, pinguecula, or normal conjunctival specimen from Chinese patients in Taiwan, where the prevalence of pterygia is high.

Three studies have addressed the presence of HPV DNA in pterygia and all used PCR amplification with a single primer (Table 3 ). These reports demonstrated big differences in frequencies, from $0 \%$ to $100 \%$, and variety of HPV types (type $6,11,16,18$ ) that could be possibly explained by the different primers used, the absence of adequate controls, small sample size (10-50 specimens), and the possible different frequencies of HPV infection in geographically distinct populations. Confirmatory larger studies in different geographic populations using more efficient primer(s) are needed to clarify the relation between HPV infection and pterygium formation.

The similar controversy occurred in the detection HPV DNA of malignant epithelial neoplasms of conjunctiva but not squamous cell papilloma of conjunctiva. ${ }^{15}$ By reviewing the published data of previous reports, HPV positive rates in conjunctival papilloma specimens were quite consistent, from $44-75 \%$ and most of the HPV types were type 6 and 11 that were classified as low risk HPV genotypes. ${ }^{15}$ But in the case of malignant epithelial neoplasms of conjunctiva, the frequencies of HPV detection varies from $0-100 \%$ and both low risk, HPV-6 and HPV-11, and high risk, HPV-16 and HPV-18, groups were found by various molecular techniques. ${ }^{15}$

Owing to different populations studied and the absence of a gold standard HPV detection technique and adequate controls in most studies published to date, ${ }^{16716}$ there are marked variations in the obtained HPV prevalence rates in pterygium. Therefore, HPV probably does not act alone in the development of pterygium and the exact role of HPV in the pathogenesis of pterygium remains unclear. The lack of HPV DNA in pterygium in this study may indicate either the HPV is not associated with pterygium formation or that the technique was not adequate for demonstration of such an association. Based on our data, we suggest that HPV is not a required cofactor in the development of pterygia.

Grant support: none

Commercial relationship: none.

K-H Chen, W-M Hsu, C-C Cheng, Y-S Li

Department of Ophthalmology, Taipei Veterans General Hospital, Taipei, Taiwan

K-H Chen, W-M Hsu

National Yang-Ming University, Taiwan

K-H Chen, C-C Cheng, Y-S Li

Division of Medical Engineering, National Health Research Institutes, Taipei, Taiwan

Correspondence to: Dr Wen-Ming Hsu, Department of Ophthalmology, Taipei Veterans General Hospital, \#201, Shih-Pai Road, Section II, Taipei,

11217 Taiwan; khchen@vghtpe.gov.tw

Accepted for publication 12 December 2002

\section{References}

1 Gallagher MJ, Giannoudis A, Herrington CS et al. Human papillomavirus in pterygium. $\mathrm{Br}$ Ophthalmol 2001;85:782-4.

2 Cilova-Atanasova B. On the pathogenesis of pterygium. Folia Med (Plovdiv) 1971;13:67-74

3 Dushku N, Hatcher SL, Albert DM, et al. p53 expression and relation to human papillomavirus infection in pingueculae pterygia, and limbal tumors. Arch Ophthalmo 1999;117:1593-9.

4 Varinli S, Varinli I, Koksal Erkisi M, et al. Human papillomavirus in pterygium. Cent $A f r$ J Med 1994:40:24-6.

5 Detorakis ET, Sourvinos G, Spandidos DA. Detection of herpes simplex virus and human papilloma virus in ophthalmic pterygium. Cornea 2001;20:164-7.

6 Detorakis ET, Drakonaki EE, Spandidos DA. Molecular genetic alterations and viral presence in ophthalmic pterygium. Int J Mol Med 2000;6:35-41.

7 Dushku N, Hatcher SL, Albert DM, et al. p53 expression and relation to human papillomavirus infection in pingueculae, pterygia, and limbal tumors. Arch Ophthalmol $1999 ; 117: 1593-9$.

Table 3 Literature reports of human papillomavirus detection in pterygia

\begin{tabular}{|c|c|c|c|c|c|}
\hline Authors (year published) & $\begin{array}{l}\text { No of } \\
\text { specimens }\end{array}$ & $\begin{array}{l}\text { Pterygium } \\
\text { (type) }\end{array}$ & Method/primer & Positive rates & $\begin{array}{l}\text { HPV types } \\
\text { (negative) }\end{array}$ \\
\hline Dolmetsch et al $(1996)^{16}$ & 16 & $?$ & Immunohistochemical stain & $100 \%$ & $16(6,11,18)$ \\
\hline Dushuku et al (1999)7 & 13 & $P+R$ & My09/My1 1 & 0 & - \\
\hline Detorakis et al $(2000)^{6}$ & 50 & $P+R$ & GP5/GP6 & $24 \%$ & 18 \\
\hline Gallagher et al $(2001)^{1}$ & 10 & $?$ & GP5/GP6 & $50 \%$ & $6,11,16$ \\
\hline Chen et al (current study) (2002) & 65 & $P$ & $\begin{array}{l}\text { MY09/MY11 } \\
\text { L1C1/L1C2-1, GP5/GP6 }\end{array}$ & 0 & - \\
\hline
\end{tabular}

$\mathrm{P}=$ primary $; \mathrm{R}=$ recurrent 
8 Grce M, Husnjak K, Magdic L, et al. Detection and typing of human papillomaviruses by of Croatian women with abnormal cytology. Eur J Epidemiol 1997:13:645-51.

9 Bell DA, Taylor JA, Paulson DF, et al. Genetic risk and carcinogen exposure: a common inherited defect of the carcinogen-metabolism gene glutathione S-transferase M1 (GSTM1) that increases susceptibility to bladder cancer. J Natl Cancer Inst 1993;85: 1159-64.

10 Husnjak K, Grce M, Magdic L, et al. Comparison of five different polymerase chain reaction methods for detection of human papillomavirus in cervical cell specimens. $J$ Virol Methods 2000;88: 125-34

11 Husniak K, Grce M, Magdic L, et al. Comparison of five different polymerase chain reaction methods for detection of human papillomavirus in cervical cell specimens. $J$ Virol Methods 2000;88: 125-34.

12 Zur Hausen H. Papillomavirus infections: a major cause of human cancers. Biochim Biophys Acta 1996;1 288:55-78.

13 McDonnell JM, McDonnell PJ, Stout WC, et squamous carcinoma of the eyelid. Arch Ophthalmol 1989;107:1631-4.

14 Laver SA, Malter JS, Meier JR. Human papillomavirus type 18 in conjunctival intraepithelial neoplasia. Am J Ophthalmol 1990;1 10:23-7

15 Eng HL, Lin TM, Chen SY, et al. Failure to detect human papillomavirus DNA in malignant epithelial neoplasms of conjunctiva by polymerase chain reaction. Am J Clin Pathol 2002; 17:429-36.

16 Dolmetsch AM, Alcocer CE, Scull JJ, et al. The presence of human papilloma virus in pterygia (abstract). Invest Ophthalmol Vis Sci 1996;37:S43

\section{Factor V Leiden mutation does not correlate with retinal vascular occlusion in white patients with Behçet's disease}

The factor $\mathrm{V}$ Leiden (FV Leiden) mutation causes resistance to activated protein $\mathrm{C}$ by substituting the $\mathrm{Glu}^{506}$ residue with arginine at the cleavage site for activated protein $\mathrm{C}$. Heterozygous carriers of the FV Leiden mutation have an increased risk of venous thrombosis between threefold and sevenfold in population based and family studies. $^{12}$ Behçet's disease is a chronic inflammatory multisystem disorder that affects young adults. The principal cause of visual loss in polymerase chain reaction in cervical scrapes al. Human papillomavirus DNA in a recurrent

this disease is recurrent retinal vein occlusion probably due to a combination of retinal vasculitis and thrombus formation. Thrombosis in Behçet's disease carries a poor ocular and systemic prognosis, so the presence of an identifiable and significant risk factor could be an indicator for anticoagulant treatment. ${ }^{3}$ Two recent studies have implicated FV Leiden in the pathogenesis of thrombosis in Turkish patients with Behçet's disease. In one study, $30 \%$ of patients with Behçet's disease complicated by thrombosis were heterozygous or homozygous for factor $\mathrm{V}$ Leiden compared to $5.9 \%$ of factor $V$ Leiden negative patients. ${ }^{4}$ In the second study, factor V Leiden was detected in $37.5 \%$ of patients with Behçet's disease and a thrombotic history, compared to $9.4 \%$ of non-thrombotic patients. ${ }^{5}$ We have previously shown in a study of 106 Middle Eastern patients with Behçet's disease and 120 racially matched controls that the prevalence of factor $\mathrm{V}$ Leiden was significantly higher among patients with ocular inflammation (odds ratio 1.67) and was even more prevalent in patients who had developed retinal vascular occlusive disease (odds ratio 2.57). ${ }^{6}$

In this current study we analysed the association between factor V Leiden and clinical features of Behçet's disease in white patients from the United Kingdom. The results show that, unlike Middle Eastern Behçet's disease patients, factor V Leiden was not associated with Behçet's disease in UK patients.

\section{Patients}

DNA samples from 53 white patients with Behçet's disease were collected from individuals attending the Behçet's disease clinic at the Medical Eye Unit, St Thomas's Hospital, London. All patients fulfilled the international criteria for Behçet's disease. Middle Eastern and Afro-Caribbean patients were excluded from this study. A total of 150 white controls from the London area were provided from our DNA bank. Patients' clinical details were recorded following full systemic and ocular examination, the diagnosis of retinal vein occlusion being recorded following fluorescein angiography.

\section{Factor V Leiden analysis}

HLA typing and detection of the FV Leiden mutation was performed using PCR-SSP as

Table 1 Clinical and genetic data on 53 white patients with Behçet's disease (BD), and 100 healthy white controls

\begin{tabular}{lll}
\hline & & No $(\%)$ \\
\hline $\begin{array}{l}\text { BD patients }(n=53) \\
\text { Sex }\end{array}$ & Male & $28(53 \%)$ \\
& Female & $25(47 \%)$ \\
Ocular disease & Yes & $39(74 \%)$ \\
& No & $11(21 \%)$ \\
HLA-B*51 & Positive & $22(42 \%)$ \\
& Negative & $31(58 \%)$ \\
FV Leiden & Positive & $2(3.8 \%)$ \\
Controls $(n=100)$ & Negative & $51(96.4 \%)$ \\
HLA-B*51 & Positive & $6(6 \%)$ \\
& Negative & $94(94 \%)$ \\
FV Leiden & Positive & $5(5 \%)$ \\
& Negative & $95(95 \%)$ \\
\hline
\end{tabular}

previously described. ${ }^{6}$ The results were analysed by generating two by two contingency tables and statistical analysis was performed using $\chi^{2}$ test.

\section{Results}

Fifty three patients (28 males, 25 female) were analysed; $74 \%(n=39)$ had ocular disease, 11 had no ocular disease, and for three patients the ocular disease status was unknown. Of those patients with ocular disease, 54\% (21/39) had retinal vein occlusion.

Twenty two of $53(42 \%)$ were HLA-B*5 $1^{+}$of whom $3 / 22(14 \%)$ were $B^{\star} 5108$, the remainder being $\mathrm{B} * 5101$ (Table 1$)$.

Only $2 / 53(3.8 \%)$ patients in this cohort of patients with Behcet's disease were heterozygous for the FV Leiden mutation (Table 1). Both patients were male, and had ocular disease, however only one of these individuals had evidence of retinal occlusion.

\section{Comment}

The factor V Leiden mutation has been linked with ocular disease in Middle Eastern patients with Behçet's disease, in particular those with proved retinal venous thrombosis. The current data on UK patients with Behçet's disease do not show a similar association. The prevalence of FV Leiden in the patient group was no different from the control group. Moreover, while both patients positive for FV Leiden had ocular disease this is against a background of a high level of eye disease in this group.

There are several possibilities that could explain the difference between the two groups. Firstly, the presence of FV Leiden in the Middle Eastern population was particularly high (17\%) and this may have accounted for the functional role of this molecule in retinal venous thrombosis in this ethnic population. By comparison, the low prevalence of the mutation in white people suggests that much larger numbers of Behçet's disease patients will need to be tested to identify any possible association. This has been supported by studies on other European patients with Behçet's disease where FV Leiden was not identified as a risk factor for systemic venous thrombosis. ${ }^{7}$ Moreover, in our previous study, we identified several patients who were homozygous for the FV Leiden mutation and were clinically blind. In a population with such a high prevalence of the mutation, homozygosity will be more common and may have biased the data in favour of an association between FV Leiden and severity of ocular disease in the patient group. ${ }^{6}$

Secondly, recent studies in relatives of individuals with venous thrombosis have shown that the presence of FV Leiden adds only a threefold risk of thromboembolism. Over half of these events were linked to other risk factors such as pregnancy, surgery, or oral contraceptives. ${ }^{8}$ This would suggest that in the general white population genetic mutations affecting proteins involved in the coagulation cascade might only be associated with thrombosis in individuals with concurrent risk factors.

Thirdly, population specific phenotypic effects have been described for other gene polymorphisms. In a worldwide survey of HIV+ and HIV individuals, a particular haplotype of the RANTES gene was associated with increased risk of acquiring HIV-1, and accelerated disease progression, in European Americans, but not African-Americans. A second RANTES haplotype was associated with delayed progression of disease in Japanese 
patients, but not in other ethnic groups of patients, probably because this haplotype is rarely found in non-Far East Asians. ${ }^{9}$ There are several other factor $\mathrm{V}$ gene polymorphisms that may be involved in white patients and these could be an area for future study.

These results suggest that interindividual and interpopulation specific genotypes are associated with disease although the phenotypic outcome remains the same. Therefore gene polymorphisms that associate with disease in one population cannot be regarded as associating with the disease in different ethnic groups. It may not be possible to identify genes involved in severity of a complex disease such as Behçet's disease, which will hold across different patient populations.

Y Chen, M R Stanford, G R Wallace Department of Ophthalmology, King's College, London SEI 7EH, UK

R W Vaughan, E Kondeatis Department of Tissue Typing, King's College, London SEI 7EH, UK

F Fortune

Department of Oral Medicine, University of Leeds, Leeds, UK

Correspondence to: Dr Graham Wallace, Academic Unit of Ophthalmology, University of Birmingham, City Hospital, Dudley Road, Birmingham B 18 7QU, UK g.r.wallace@bham.ac.uk

Accepted for publication 15 December 2002

\section{References}

1 Svensson PJ, Dahlback B. Resistance to activated protein $\mathrm{C}$ as a basis for venous thrombosis. N Engl J Med 1994;330:517-22.

2 Martinelli I, Mannucci PM, De Stephano V, et al. Different risks of thrombosis in four coagulation defects associated with inherited thrombophilia: a study of 150 families. Blood 1998;92:2353-8.

3 Mochizuki $\mathbf{M}$, Akduman L, Nussenblatt RB. Behçet's disease. In: Pepose JS, Holland GN, Wilhelmus KR, eds. Ocular immunology and inflammation. St Louis: Mosby, 1996:663-75.

4 Oner AF, Gurgey A, Gurler A, et al. Factor V Leiden mutation in patients with Behçet's disease. J Rheumatol 1998;25:496-8.

5 Gul A, Ozbek U, Ozturk C, et al.

Coagulation factor $\mathrm{V}$ gene mutation increases the risk of venous thrombosis in Behçet's disease. Br J Rheumatol 1996;35: 1 178-80.

6 Verity DH, Vaughan RW, Madant W. Factor $\mathrm{V}$ Leiden mutation is associated with ocular involvement in Behçet's Disease. Am J Ophthalmol 1999:128:352-6.

7 Espinosa G, Font J, Tassies D, et al. Vascular involvement in Behçet's disease: relation with thrombophilic factors, coagulation, activation and thrombomodulin. Am J Med

$$
\text { 2002; 1 12:37-43. }
$$

8 Martinelli I, Bucciarelli P, Margaglione M, et al. The risk of venous thromboembolism in family members with mutations in the genes of factor $\mathrm{V}$ or prothrombin or both. $\mathrm{Br} J$ Haematol 2000;111:1223.

9 Gonzalez E, Dhada R, Bamshad M, et al. Global survey of genetic variation in CCR5 RANTES, and MIP $1 \alpha$ : impact on the epidemiolog yof the HIV pandemic. PNAS 2001;98:5199-204.

\section{Localised corneal amyloidosis associated with herpetic keratitis}

Amyloid diseases are secondary protein structure diseases in which insoluble protein fibrils accumulate extracellularly. Twenty different types of fibrils have been described in human amyloidosis, each with a different clinical picture. Amyloidosis can be generalised, affecting multiple organ systems, or localised and can

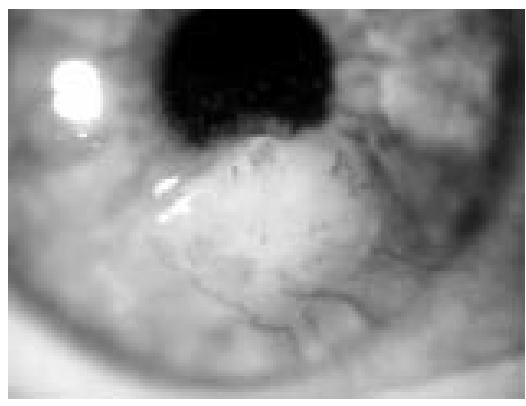

Figure 1 Clinical appearance of the lesion on presentation. Note the gelatinous appearance and the marked vascularisation.

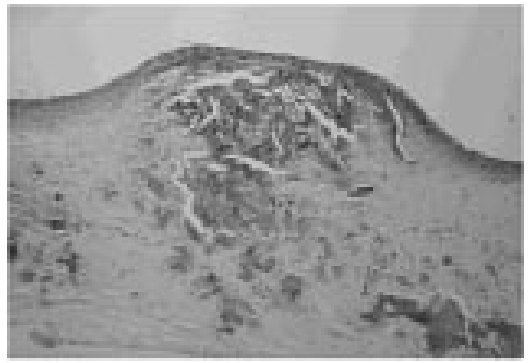

Figure 2 Photomicrograph of a Congo red stained section of the lesion showing amyloid in the corneal stroma.

affect almost any organ of the body. In the eye amyloid is the material commonly seen in lattice corneal dystrophy. Cases of localised corneal amyloidosis have been reported in literature but are quite rare. ${ }^{1-4}$ We report a case of localised corneal amyloidosis presenting as a large raised gelatinous vascularised lesion in a patient with long standing herpetic keratitis.

\section{Case report}

A fit and healthy 34 year old woman was a tertiary referral to the corneal clinic with a long standing history of a lesion on her right cornea. The initial presentation as a teenager was of a red sore right eye with a corneal ulcer that was treated as a bacterial ulcer for a few years and later on as recurrent herpetic keratouveitis. She had had numerous intermittent courses of combined topical antivirals and steroids with resolution of symptoms. Over the past 2 years she was noted to develop a raised vascularised lesion over the right cornea, which gave a constant foreign body sensation and occasional episodes of pain. It was the appearance of the lesion and the discomfort rather than the reduced visual acuity, which prompted her to seek treatment. On presentation in the clinic she had a visual acuity of 6/36 right (6/24 with pinhole) and 6/6 left eye. Anterior segment examination showed a large, raised, gelatinous, slightly nodular, vascularised lesion on the right cornea (Fig 1). The rest of the anterior segment examination was normal. Ocular adnexae did not show any signs of chronic lid disease. The corneal sensation was intact. A superficial keratectomy was performed under general anaesthesia to excise the lesion. Histopathological examination of the specimen revealed a diagnosis of amyloidosis (Fig 2).

\section{Comment}

Amyloidosis can be either primary or secondary, both of which can be further classified into systemic and local disease. Systemic primary amyloidosis can affect various ocular structures presenting as papules or purpura on the lids, conjunctival deposits, external ophthalmoplegia, vitreous opacities, and glaucoma. Secondary systemic amyloidosis rarely affects the eye, although a case of conjunctival amyloidosis has been reported in a patient with rheumatoid arthritis. ${ }^{5}$

Stafford and Fine, for the first time in 1966, reported a case of corneal amyloidosis in a young girl with ocular complications of retinopathy of prematurity. ${ }^{6}$ Primary familial amyloidosis, which presents as nodular white subepithelial protuberances in the central cornea, has been postulated to be autosomal recessive. ${ }^{1}$ In secondary localised corneal amyloidosis, the material is deposited as a result of chronic inflammation and irritation from scarred lids from trachoma, trichiasis, or long standing corneal scars..$^{2-4-9}$ To the best of our knowledge its association with herpetic keratitis has not been reported.

Macpherson et al retrospectively examined 200 specimens of corneas removed for various reasons specifically for amyloid deposits and found it present in seven cases $(3.5 \%) .^{7}$ It has been proposed that the basal cells of the corneal epithelium are responsible for the synthesis of amyloid, ${ }^{2}$ although other sources have been also proposed. ${ }^{8}$

D Tejwani, A Azuara-Blanco

Department of Ophthalmology Aberdeen Royal Infirmary, Grampian University Hospitals, UK

J MacKenzie

Department of Pathology

Correspondence to: Augusto Azuara-Blanco, The Eye Clinic, Aberdeen Royal Infirmary, Aberdeen AB25 2ZN, UK: aazblanco@aol.com

Accepted for publication 16 December 2002

\section{References}

1 Stock EL, Kielar RA. Primary familial amyloidosis of the cornea. Am J Ophthalmol 1976;82:266-71.

2 Kigasawa K, Mashima Y, Yogata T, et al. A histopathological study of corneal amyloidosis secondary to trichiasis. Nippon Ganka Gakkai Zasshi 1996;100:394-400.

3 Watts J, Frank H. Corneal amyloidosis. $\mathrm{Br} J$ Ophthalmol 1989:73:674-6.

4 Brownstein M, Elliot R. Ophthalmologic aspects of amyloidosis. Am J Ophthalmol 1970;69:423-30.

5 Blodi FC Apple DJ. Localised conjunctival amyloidosis. Am J Ophthalmol 1979;88:346-50.

6 Stafford WR, Fine BS. Amyloidosis of the cornea. Report of a case without conjunctival involvement. Arch Ophthalmol

1966;75:53-63.

7 McPherson SD Jr, Kiffney GT Jr, Freed CC. Corneal amyloidosis. Am J Ophthalmol 1966;62:1025-33.

8 Garner A. Amyloidosis of the cornea. Br J Ophthalmol 1969:53:3-81.

9 Ramsey MS, Fine BS, Cohen SW. Localised corneal amyloidosis. Case report with electron microscopic observations. Am J Ophthalmol 1972;73:560-5

\section{Bilateral macular staphylomas in a patient with cone dystrophy}

A posterior staphyloma is characterised by scleral ectasia and is pathognomonic for pathological myopia. ${ }^{12}$ Posterior staphylomas are classified in to five types based on the anatomic location. ${ }^{1}$ Type 1 staphylomas extend from the nasal border of the optic nerve into the macular region and are the most frequent staphyloma seen in myopes. ${ }^{1}$ Type 2 staphylomas are centred on the macula while type 3 staphylomas are centred on the optic 


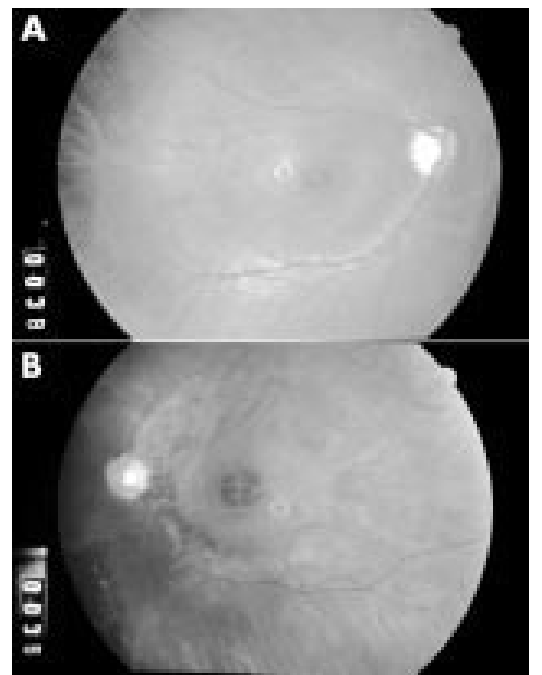

Figure 1 (A) and (B) Bilateral macular staphylomas in a patient with cone dystrophy. There are macular retinal pigment epithelial changes consistent with cone dystrophy. The retinal vessels in both eyes appear to dive posteriorly into staphylomas that are centred around the macula (type 2 staphyloma)

disc without macular extension. ${ }^{1}$ Type 4 staphylomas are located nasal to the optic disc and type 5 staphylomas develop inferior to the optic disc. ${ }^{\prime}$ Staphylomas can be associated with multiple complications including retinal pigment epithelial atrophy, lacquer cracks, retinal and subretinal haemorrhages, and choroidal neovascularisation.

This report describes a patient with undiagnosed, bilateral type 2 macular staphylomas compounded by cone dystrophy. To the best of our knowledge, this is a novel association not reported in the literature and with potential therapeutic implications.

\section{Case report}

A 32 year old white woman presented to the Wilmer Ophthalmological Institute, Baltimore, MD, for a second opinion. She reported having progressively worsening vision since childhood and was diagnosed with cone-rod dystrophy at age 18 by an outside ophthalmologist. She experienced photophobia both indoors and outdoors. She denied recent changes in her vision. Past ocular history was

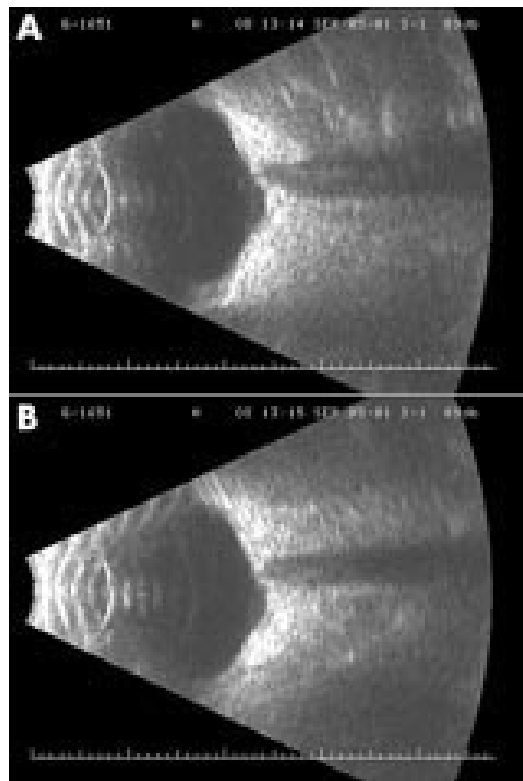

Figure 3 (A) Horizontal B-scan ultrasound of the right eye. The depth and width of the macular staphyloma is $1.5 \mathrm{~mm}$ and $4.6 \mathrm{~mm}$ respectively. (B) Horizontal B-scan ultrasound of the left eye. The depth and width of the macular staphyloma is $1.0 \mathrm{~mm}$ and $4.2 \mathrm{~mm}$ respectively.

otherwise significant for a remote history of corneal abrasion in the right eye. Past medical history and family history were noncontributory.

On ophthalmological examination, her uncorrected visual acuity was 20/200-2 in the right eye and 20/200-1 in the left eye. Retinoscopic reflex and refraction were variable and significant for mild myopia. Refraction did not improve her vision. There was no relative afferent pupillary defect and extraocular movements were normal. There was no evidence of nystagmus. Slit lamp biomicroscopy of the anterior segment was unremarkable. Dilated fundus examination showed a tilted optic nerve head in each eye. There were bilateral macular retinal pigment epithelia changes consisting of a ring of hypopigmentation surrounding an area of mildly increased pigmentation centrally (Fig 1). The retinal vessels in each eye appeared to dive into posterior staphylomas (Fig 1). The staphylomas were centred around the macula in each eye. The peripheral retina in each eye was otherwise normal.

Fluorescein angiography demonstrated mottled hyperfluorescence without leakage corresponding to the retinal pigment epithelium (RPE) changes (data not shown). Goldmann visual fields were remarkable for central scotomas in both eyes with peripheral isoptres full to II-4 stimulus in the right eye and I-4 stimulus in the left eye (Fig 2). A B-scan showed bilateral staphylomas with macular involvement (Fig 3). On electroretinography, photopic responses were markedly reduced. The dim scotopic responses were normal. The mixed scotopic responses were $90 \%$ of normal in the right eye and $97 \%$ of normal in the left eye. There were markedly reduced photopic flash and flicker responses, with a questionable response of $10 \%$ of the normal amplitude. Pelli-Robson contrast sensitivity testing was depressed at $1.2 \log$ units in a dim environment (normal $=1.65$ ). D15 colour testing detected four major and three minor errors in the right eye, and five major and two minor errors in the left eye. A therapeutic red tinted contact lens was prescribed to eliminate the photophobia and aversion to light due to cone dystrophy, and thereby to reduce the level of visual dysfunction ${ }^{45}$ After 1 month of wear, the patient reported being a lot more comfortable in bright surroundings. She did not have to squint as much as before using these lenses, was able to sustain prolonged eye contact with other individuals, had improved face recognition and demonstrated improved posture. Visual acuity was $20 / 125$ in each eye tested separately and 20/80-2 when both eyes were tested together.

\section{Comment}

In summary, we have described a patient whose findings are consistent with a diagnosis of cone dystrophy compounded by bilateral macular staphylomas. We believe that this does not represent congenital achromatopsia given the absence of nystagmus and the history of progressively worsening vision. Although there is a report of familial cone dystrophy with bilateral macular colobomata, ${ }^{6}$ we are unaware of a case of bilateral macular staphylomas associated with cone dystrophy. To our knowledge, this case represents a previously unreported association of cone dystrophy with macular staphylomas. Awareness of this association will hopefully contribute to proper diagnosis as this finding had presumably been missed in previous ophthalmological examinations.

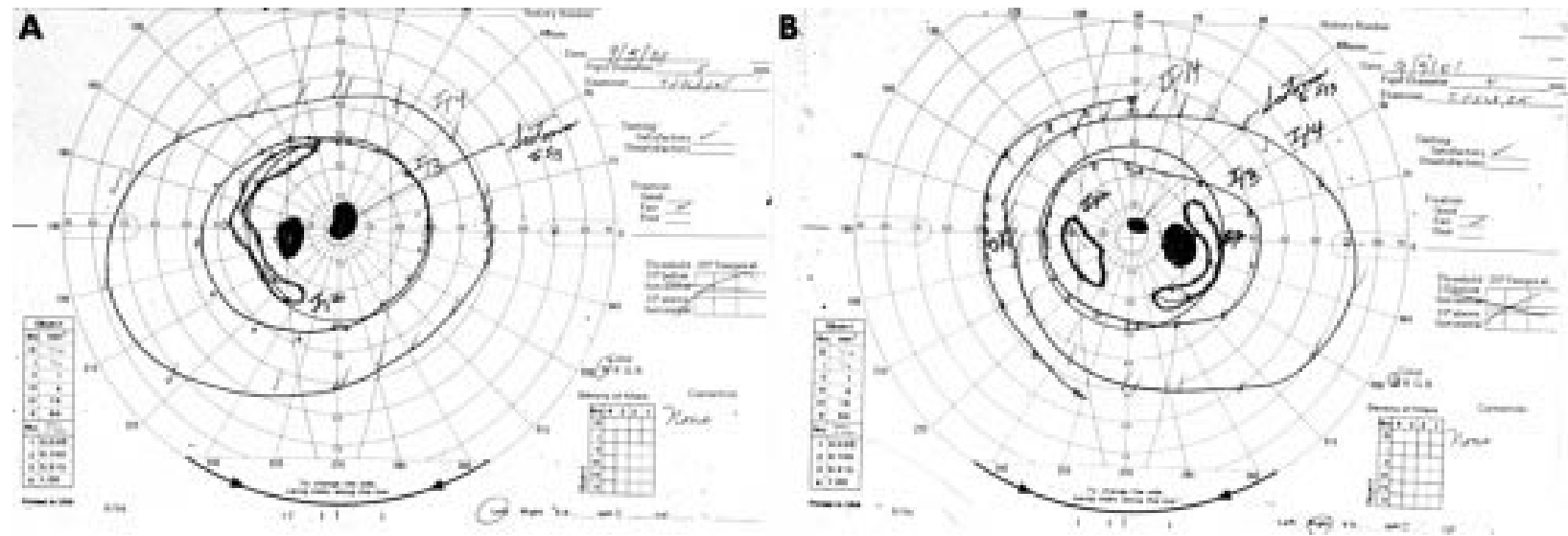

Figure 2 (A) and (B) Goldmann visual fields in both eyes demonstrate central scotomas with peripheral isoptres full to ll-4 stimulus in the right eye (bottom right) and I-4 stimulus in the left eye (bottom left). 
Given the significant association of macular staphylomas with numerous complications listed above, especially the risk for choroidal neovascularisation and haemorrhage, such patients should receive counselling regarding its symptoms and receive periodic comprehensive ophthalmological examinations.

Financial interests: None.

Financial support: None.

R S Apte, J S Sunness

The Retinal Vascular Center, The Wilmer Ophthalmological Institute, The Johns Hopkins University School of Medicine, Baltimore, MD, USA

R S Apte, B G Goldstein The Vitreoretinal Division

W L Park, J S Sunness Lions Vision Center

R Z Raden, M J Elman Elman Retina Group, PA, Baltimore, MD, USA

Correspondence to: Janet S Sunness, MD, The Wilmer Ophthalmological Institute, The Johns Hopkins University School of Medicine, $550 \mathrm{~N}$ Broadway, 6th Floor, Baltimore, MD 21205 , USA jsunness@jhmi.edu

Accepted for publication 2 January 2003

\section{References}

1 Quaranta M, Brindeau C, Coscas G, et al. Multiple choroidal neovascularizations at the border of a myopic posterior macular staphyloma. Graefes Arch Clin Exp Ophthalmol 2000;238:101-3.

2 Curtin BJ, Carlin DB. Axial length measurements and fundus changes in the myopic eye. Am J Ophthalmol

$$
1971 ; 71: 42-53
$$

3 SteidI SM, Pruett RC. Macular complications associated with posterior staphyloma. Am J Ophthalmol 1997;123:181-7.

4 Young RSL, Krefman RA, Fishman GA. Visual improvements with red-tinted glasses in a patient with cone dystrophy. Arch Ophthalmol 1982;100:268-71.

5 Zisman F, Harris MG. Therapeutically tinted contact lenses. In: Harris MG, London R, eds. Contact lenses: treatment options for ocular disease. St Louis: Mosby, 1996: 105-22.

6 Miller SA, Bresnick G. Familial bilateral macular colobomata. Br J Ophthalmol 1978;62:261-4.

\section{Bloody tears, and more! An unusual case of epistaxis}

A 56 year old woman presented to the emergency department with a 2 hour history of bleeding from the right nostril. She had tried to stop it by pinching her nose but had then also experienced bleeding from her right eye and ear (Fig 1).

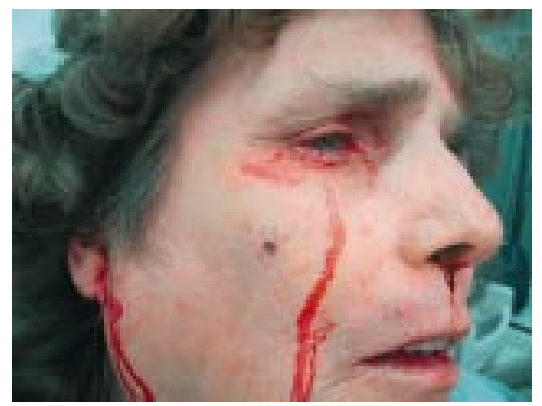

Figure 1 Right sided haemolacna and bloody otorrhoea in the context of epistaxis. Photograph reproduced with the consent of the patient.
Bloody tears, or haemolacria, are an occasional feature of hereditary haemorrhagic telangiectasia, and tumours of the lacrima apparatus. $^{2}$ In the emergency department, however, they are more commonly encountered accompanying epistaxis. To date, Medline lists only a single case report of haemolacria in this context, ${ }^{3}$ and the photograph presented here may well be the first of the phenomenon.

Its anatomical basis lies in the intimate connection of nose and eye via the lacrimal apparatus. An increase in pressure within the nasal cavity during epistaxis-for example, by pinching or blowing the nose, can cause retrograde flow of blood through the system and thus lead to bloody tears emerging from the ipsilateral eye.

As our patient had longstanding perforation of both tympanic membranes, the blood in her nose was also able to travel retrograde via the auditory tube and middle ear into the external auditory canal. This led to the additional bleeding from the right ear.

Bleeding was readily controlled by nasal sponge tamponade. The patient made an uneventful recovery.

M F Wiese

Department of Emergency Medicine King's College Hospital, Denmark Hill, London SE5 9RS, UK wiese@doctors.org.uk

Accepted for publication 23 December 2002

\section{References:}

1 Soong HK, Pollock DA. Hereditary hemorrhagic telangiectasia diagnosed by the ophthalmologist. Cornea 2000;19:849-50.

2 Levine MR, Dinar Y, Davies R. Malignant melanoma of the lacrimal sac. Ophthalmic Surg Lasers 1996;27:318-20.

3 Banta RG, Seltzer JL. Bloody tears from epistaxis through the nasolacrimal duct. Am J Ophthalmol 1973;75:726-7.

\section{Haemorrhagic toxoplasmic} retinochoroiditis: description of an unusual clinical presentation

Toxoplasmic retinochoroiditis (TRC) is an infectious disease caused by the protozoan Toxoplasma gondii. This infection affects many organs including the eyes. Most of the time ocular involvement occurs after a transplacental transmission, throughout pregnancy, but the infection can also be acquired. In immunocompetent patients, TRC is the most common cause of infection affecting the posterior segment. Clinically, the lesion appears as a white focal necrosis involving the ful thickness of the retina, at the margin of an old pigmented chorioretinal scar. A vitreous inflammation is usually present and occasionally vasculitis is observed.

We report the case of a healthy patient who developed a unilateral haemorrhagic retinochoroiditis (RC). The investigations performed were positive for a TRC.

\section{Case report}

A 45 year old African man was referred with a 10 day history of a painless progressive visual loss affecting the left eye. No other ophthalmological or systemic complaints were present. His past medical history was unremarkable.

Ophthalmological examination disclosed a vision of $20 / 20$ in the right eye without correction and in the left eye the best visual acuity was 20/200. Anterior segment examination was normal in the right eye but revealed a mild inflammation in the left.
Intraocular pressure was within the normal limits in both eyes. Left eye fundus examination showed a vitreous inflammation (cells: $++)$ and a whitish retinochoroidal lesion surrounded by a large preretinal haemorrhage. Hard exudates were present in the macular area as well as a retinal oedema (Fig l).

Investigations revealed an erythrocyte sedimentation rate of $6 \mathrm{~mm}$ in the first hour (reference range 1-12), and a normal white blood count. Serological testing for toxoplasmosis gave negative results for IgM but IgG titres were $40 \mathrm{IU} / \mathrm{ml}$ (reference range $>3$ ). Serology tests for Borrelia burgdorferi, Treponema pallidum, and HIV were normal. An acute infection was suspected and we decided to perform an anterior chamber tap. Polymerase chain reaction (PCR) (toxoplasmosis, CMV, HSV, VZV) gave negative results, but the GoldmannWittmer coefficient was 13.64 (reference range $<4$ ), revealing a local production of anti-toxoplasmic immunoglobulins. Tests for sarcoidosis and for connective tissue disorders were negative. Immunoglobulin electrophoresis, quantitative immunoglobulin levels, CD4CD8 lymphocyte count, C3-C4 and CH50 examination were within the normal range. PPD skin test was just positive $(7 \mathrm{~mm})$. Chest $x$ ray was normal.

Based on these findings, a TRC was diagnosed. The patient was treated with sulphadiazine $(4 \times 1 \mathrm{~g} /$ day $)$, pyrimethamine $(2 \times 25 \mathrm{mg} /$ day $)$ and folinic acid, during 6 weeks. Topical steroids and mydriatic drops were also prescribed. Prednisone ( $1 \mathrm{mg} / \mathrm{kg}$ ) was introduced, at tapering doses, during the treatment.

After 3 months, visual acuity returned to $20 / 20$ without a correction in the left eye Anterior segment examination was normal Left eye posterior segment examination disclosed a regression of the haemorrhages and a white chorioretinal scar with hard exudates located around the fovea. Kyrieleis's plaque were observed along the inferior papillary arterial vessel (Fig 2).

The patient was followed during 2 years and no reactivation of the RC was observed Moreover, tests to exclude an immune disease were still within the normal limits (HIV immunoglobulin electrophoresis, quantitative immunoglobulin levels, PPD skin test, CD4 CD8 lymphocytes count, C3-C4, and CH50).

\section{Comment}

The most classic clinical presentation of an active toxoplasmic lesion is that of a whitish and oedematous necrotising RC close to an old pigmented scar. A severe vitreous

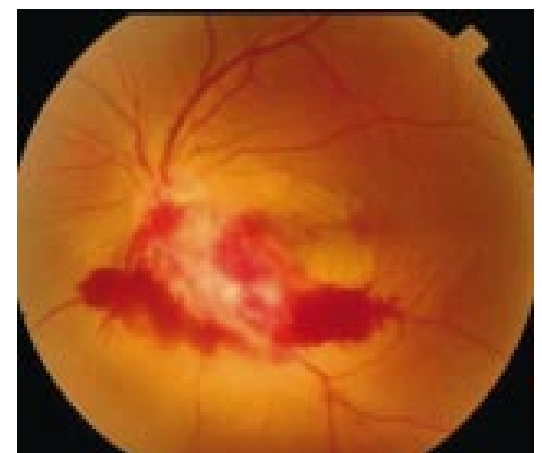

Figure 1 Fundus of the left eye. Presence of an oedematous retinochoroidal lesion surrounded by a large preretinal haemorrhage. Hard exudates are observed in the macular area. 


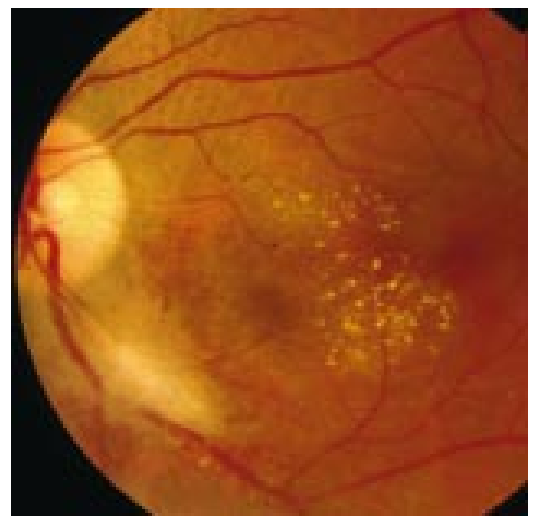

Figure 2 Fundus of the left eye $(3$ months after treatment). Regression of the haemorrhages. Presence of a whitish retinochoroidal scar with hard exudates around the fovea. Kyrieleis's plaques are observed along the inferior papillary arterial vessel.

inflammatory reaction is usually associated, appearing as a "headlight in the fog." Lesions can occur anywhere in the posterior segment but most of the time, they are located in the macular area, affecting one or both eyes. Associated findings include the presence of an inflammatory sheathing of retinal vessels. ${ }^{1}$

However, a variety of clinical presentations have been reported in the past; Friedmann $e$ $a l^{2}$ described the presence grey-white fine punctuate lesions affecting the deep retina with a mild vitreous inflammation. Direct optic nerve involvement by the protozoan was described by Zimmermann in 1956. ${ }^{3}$ More recently, various clinical aspects of TCR were described in immunocompromised hosts, appearing as diffuse areas of retinal necrosis ${ }^{4}$ or as a bilateral military retinitis. ${ }^{5}$

Ocular occlusive vasculitis can be observed in inflammatory diseases including Behçet's syndrome, sarcoidosis and systemic lupus erythematosus, in infectious disorders (syphilis, acute retinal necrosis), and in TCR. Branch artery obstruction has been reported when a vessel passes through an acute $\mathrm{TCR}^{6}{ }^{6 \mathrm{6a}}$ as well as retinal vein occlusion. ${ }^{78}$

The case reported here was diagnostically challenging as the fundus appearance was not characteristic of classic TCR. In fact, haemorrhages are more frequently found in viral infections such as cytomegalovirus retinitis. This feature could be explained by damage to the vascular wall passing through the $\mathrm{RC}$, without signs of a vascular obstruction.

This case demonstrates the importance of including toxoplasmosis in the differential diagnosis of unilateral haemorrhagic RC in immunocompetent patients.

E Baglivo, A B Safran Clinique d'Ophtalmologie, Hôpitaux Universitaires de Genève, Rue Alcide-Jentzer, 22-CH, 05 Geneva, Switzerland

Correspondence to: Edoardo Baglivo, MD, Clinique d'Ophtalmologie, rue Alcide-Jentzer, 22, CH-1205 Geneva, Switzerland; Edoardo.Baglivo@hcuge.ch

Accepted for publication 2 January 2003

\section{References}

1 Gass DM. Steroscopic atlas of macular disease: diagnosis and treatment. $3 \mathrm{rd}$ ed. $\mathrm{Vol}$ 2. St Louis: CV Mosby, 1987;464-9.

2 Friedmann CT, Knox DL. Variations in recurrent active toxoplasmosic retinochoroiditis. Arch Ophthalmol 1969;81:481-3.
3 Zimmermann LE. Diseases of the optic nerve: pathology of demyelinating diseases. Trans Am Acad Ophthalmol 1956;60:46-68.

4 Holland GN, Engstrom Re, Glasgow BJ, et al Ocular toxoplasmosis in patients with the acquired immunodeficiency syndrome. Am J Ophthalmol 1988;106:653-67.

5 Berger BB, Egwuagu CE, Freeman W, et al Miliary toxoplasmosic retinitis in acquired immunodeficiency syndrome. Arch Ophthalmol 1993:111:373-6.

6 Braunstein RA, Gass JD. Branch artery obstruction caused by acute toxoplasmosis. Arch Ophthalmol 1980;98:512-13.

ba Fardeau C, Rao NA, Cassoux N, et al. Diagnosis of toxoplasmic retinochoroiditis with atypical clinical features. Am J Ophthalmol 2002; 134: 196-203

7 Rose GE. Papillitis, retinal neovascularisation and recurrent retinal vein occlusion in toxoplasma retinochoroiditis: a case repor with uncommon clinical signs. Aust NZ Ophthalmol 1991;19:155-7.

8 Gentile RC, Berinstein DM, Oppenheim R, et al. Retinal vascular occlusions complicating acute toxoplasmic retinochoroiditis. Can J Ophthalmol 1997;32:354-8.

\section{Topical dorzolamide and} metabolic acidosis in a neonate

We describe a neonate with bilateral Peter's anomaly who became unwell and developed a metabolic acidosis after commencing topical dorzolamide. He was fully investigated to exclude other causes of acidosis, and subsequently improved on discontinuation of topical treatment. To the best of our knowledge there have been no reports of topical carbonic anhydrase inhibitors causing metabolic acidosis in children or adults.

A 5 day old boy was referred to a tertiary paediatric ophthalmology unit with bilateral corneal opacities for consideration of penetrating keratoplasty. He had a normal Apgar score at delivery at 35 weeks' gestation and weight $2.3 \mathrm{~kg}$. In addition, he had had ful screening investigations including blood gases, abdominal ultrasound, and DMSA scans because of a prenatal history of intrauterine growth retardation with suspicion of a single kidney.

Ocular examination revealed total left corneal opacification and a small opacity of the right cornea inferiorly. Intraocular pressures measured were normal but since digitally the eyes felt firm and applanation tonometry is unreliable in thinned corneas, he was commenced on Trusopt (MSD) eye drops, three times daily to both eyes. He was to be reviewed 2 weeks later.

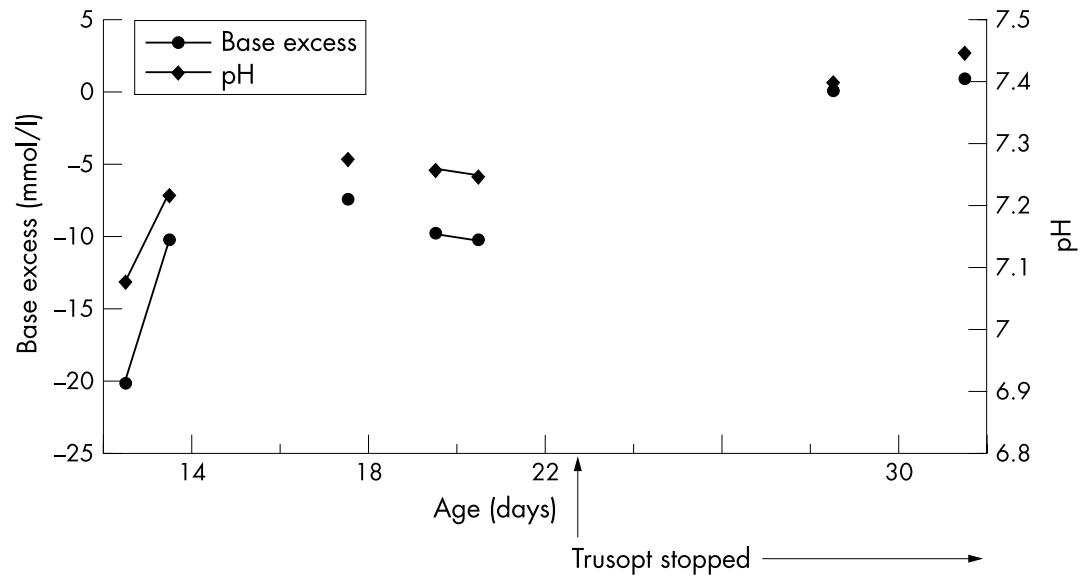

Figure 1 Trend in metabolic acidosis over time.
Seven days following the commencement of Trusopt at his regular paediatric follow up appointment, he was found to be sleepy with poor feeding and poor capillary refill. There was no history of diarrhoea or vomiting. Arterial blood gases revealed a metabolic acidosis with a pH 7.08, $\mathrm{PCO}_{2} 4.2 \mathrm{kp}, \mathrm{Po}_{2} 11.3 \mathrm{kp}$ and bicarbonate $9.3 \mathrm{mmol} / \mathrm{l}$ and base excess of -20.2. There were no markers of infection with negative blood, urine, stool, throat, and nasal cultures. Anion gap, serum electrolytes, liver function and urinalysis for $\mathrm{pH}$, specific gravity, and electrolytes were also unremarkable. Renal ultrasound and DMSA scan showed a normal functioning single right kidney.

As the cause for the metabolic acidosis at this stage was unknown he was given intravenous cefotaxime, flucloxacillin, half correction bicarbonate infusion followed by oral sodium bicarbonate supplements for 3 days. He showed some improvement with treatment; however, he remained significantly acidotic and unwell. At routine ophthalmic treatments, the eye drops were stopped and he showed spontaneous next-day resolution of his acidosis. He symptomatically improved and gained weight over the subsequent few days (Fig 1).

Topical dorzolamide has been shown to cause significant reduction in intraocular pressure (IOP) in children and is well tolerated. ' Secondary glaucoma is well recognised in cases of Peter's anomaly and raised IOP is well known to cause corneal clouding. ${ }^{2}$ Congenital corneal opacities necessitate urgent treatment in order to reduce amblyopia, and therefore it is essential to exclude glaucoma. Topical Trusopt (MSD) is used routinely at the department of ophthalmology, Great Ormond Street, as it is thought to have lower potential for adverse systemic effects than topical $\beta$ blockers.

Topical dorzolamide is a potent inhibitor of CA-II ${ }^{1}$ and this inhibition decreases the rate of aqueous humour secretion consequently lowering IOP. In the proximal renal tubule CA-II is also required to sustain maximal rates of $\mathrm{HCO}_{3}$ reabsorption. Significant systemic inhibition of carbonic anhydrase has not been observed and there has been an absence of demonstrable metabolic effects in adults. ${ }^{2-6}$ However, with the oral carbonic anhydrase inhibitor, acetazolamide, the renal carbonic anhydrase involvement and acidosis have been shown to be proportionally related to the plasma concentration levels of the drug. The dose per $\mathrm{kg}$ systemic absorption of topically review 5 days later, while free of all other 
administered dorzolamide would be expected to be higher in neonates/infants of lower body weight compared with adults.

Metabolic acidosis with normal anion gap and serum electrolytes in the absence of diarrhoea, as in this case, is more likely to be due to proximal renal tubular bicarbonate loss. Spontaneous improvement of the acidosis on termination of the topical dorzolamide is strongly suggestive of the culpability of dorzolamide. It is unclear as to why this happened, but factors such as prematurity, low birth weight, renal tubular immaturity, and one functioning kidney may have led to poor handling of drug elimination at a higher systemic concentration. Although we feel dorzolamide is a relatively safe topical antihypertensive treatment, this case underlines the need for caution when treating neonates.

S Morris, V Geh, K K Nischal Department of Ophthalmology, Great Ormond Street Hospital for Children, London WCIN 3JH,

S Morris, V Geh, K K Nischa Visual Science Unit, Institute of Child Health, London, UK

S Sahi, M A S Ahmed Department of Paediatrics, King George Hospital, Barley Lane, llford, IG3 8YB, UK

Correspondence to: Mr Ken K Nischal, Department of Ophthalmology, Great Ormond Street Hospital for Children, London WCIN 3JH, UK kkn@btinternet.com

Accepted for publication 3 January 2003

\section{References}

1 Portellos M, Buckley EG, Freedman SF. Topical versus oral carbonic anhydrase inhibitor therapy for pediatric glaucoma. J AAPOS 1998:243-7.

2 Deluise VP, Anderson DR. Primary infantile glaucoma (congenital glaucoma). Review. Surv Ophthalmol 1983;28:1-19.

3 Sugrue MF. Pharmacological and ocular hypotensive properties of topical carbonic anhydrase inhibitors. Progr Ret Eye Res 2000;19:87-112.

4 Strahlman E, Tipping R, Vogel R. The Dorzolamide Dose-response Study Group. A six-week dose-response study of the ocular hypotensive effect of dorzolamide with a one-year extension. Am J Ophthalmol 1996;1 22:183-94.

5 Biollaz J, Munafo A, Buclin T, et al. Whole-blood pharmacokinetics and metabolic effects of the topical carbonic anhydrase inhibitor dorzolamide. Eur J Clin Pharmacol 1995;47:453-60.

6 Adamsons I, Clineschmidt C, Polis A, et al. The Additivity Study Group. The efficacy and safety of dorzolamide as adjunctive therapy to timolol maleate gellan solution in patients with elevated intraocular pressure. J Glaucoma 1998;7:253-60

\section{Recurrent infectious crystalline keratopathy caused by different organisms in two successive corneal grafts in the same patient}

Infectious crystalline keratopathy (ICK) is a rare complication of penetrating keratoplasty characterised by an indolent infectious keratitis in which needle-like, branching crystalline opacities are seen within the corneal stroma, in the absence of appreciable corneal or anterior segment inflammation. ${ }^{1}$ We report an unusual case of recurrent ICK which occurred in two successive corneal grafts.

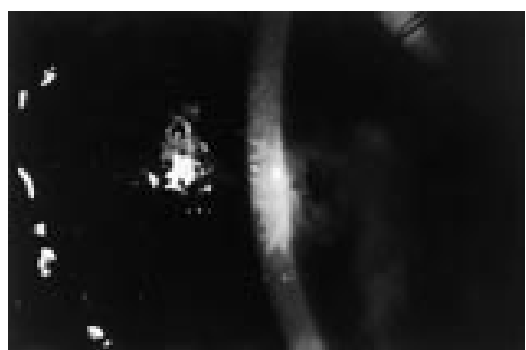

Figure 1 Infectious crystalline keratopathy due to Streptococcus viridans in the first corneal graft. Except for a small erosion over the central area of the lesion, the corneal epithelium was intact. There was no corneal, limbal, or anterior chamber inflammation.

\section{Case report}

A 63 year old man underwent penetrating keratoplasty for aphakic bullous keratopathy. The immediate postoperative course was uneventful. Topical corticosteroid (dexamethasone $0.1 \%$ ) was initially given four times daily, and then was tapered to twice daily. Seven months after transplantation, visual acuity decreased to counting fingers with no other symptoms. Slit lamp examination showed a focal area of non-suppurative branching intrastromal white opacities (Fig 1). Corneal scrapings for diagnostic smears and cultures were performed. Microscopic examination of the smears showed dense groupings of many Gram positive cocci with no inflammatory cells. Cultures grew Streptococcus viridans and were negative for fungi. The patient was treated hourly with two fortified antibiotic eyedrops (amikacin, vancomycin) and topical rifamycin. Topical antibiotic therapy was gradually tapered over 12 months. Topical dexamethasone was withdrawn and topical ciclosporin was used to maintain an immunosuppression. Despite intensive treatment with appropriate antibiotics, ICK increased in size and evolved simultaneously towards abscess and acute rejection. The subsequent corneal condition was severe residual scarring of the central cornea with diffuse neovascularisation. A second penetrating keratoplasty was then performed 19 months after the first transplantation. Topical dexamethasone, ciclosporin, and rifamycin were given four times daily. Three months after the second graft, slit lamp examination showed a large central epithelia defect with multiple diffuse white opacities confined to the anterior stroma. These multiple opacities merged into a larger confluent dense opacity near the continuous suture (Fig 2). Cytological studies and cultures of the corneal scrapings were performed. Light microscopy disclosed aggregations of many fungi with no inflammatory cells. Cultures yielded Candida albicans sensitive to amphotericin B and fluconazole. Bacterial cultures were negative. Topical amphotericin B was started every hour, along with oral fluconazole. Corticosteroids were stopped and topical ciclosporin was maintained. Despite intensive treatment, the infectious keratopathy slowly worsened over 6 months and the corneal infiltrates were replaced by scarring and neovascularisation.

\section{Comment}

Typically, ICK develops in a corneal graft after long term use of topical corticosteroids. Chronic topical corticosteroids used to prevent graft rejection produces relative immunosuppression allowing infection to develop

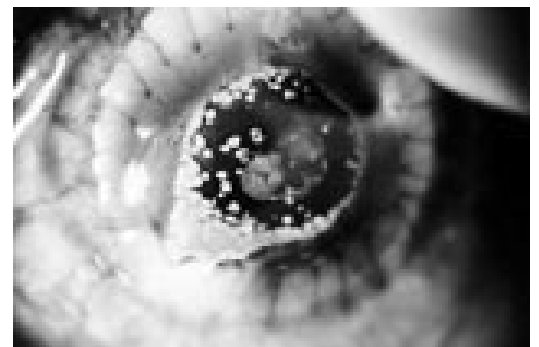

Figure 2 Slit lamp photography showing a large central epithelial defect with multiple diffuse white opacities due to Candida albicans in the second corneal graft. The remaining graft was clear. There were no signs of ocular inflammation and no symptoms.

with little or no inflammation in the cornea Gram positive cocci, usually Streptococcus viridans, are commonly isolated from ICK lesions, but other bacteria, fungi, and mixed infections have been reported..$^{2-5}$ To the best of our knowledge, recurrent ICK has never been reported in two successive corneal grafts and with two different organisms. Appropriate laboratory evaluation is therefore necessary to guide specific antimicrobial therapy. Discontinuation of topical steroids with aggressive antibiotic therapy may suffice, but continued infection, vascularisation, or scar formation may sometimes affect visual acuity and corneal graft survival. In this case, medical treatment failed, despite in vitro susceptibility of micro-organisms to antibiotics and antifungal drugs. Moreover, immunosuppression (that is, corticosteroids, ciclosporin), necessary to prevent graft rejection, worsened the infection and did not prevent the acute rejection process from developing.

In conclusion, this case suggests that local immunosuppression and factors related to the patient ocular surface may be predisposing factors for the development of ICK.

O Touzeau, T Bourcier, V M Borderie, L Laroche

Quinze-Vingts National Center of Ophthalmology, Paris, France

Correspondence to: Tristan Bourcier, MD, PhD, Ophthalmology 5, Quinze-Vingts National Center of Ophthalmology, 28 rue de Charenton 75012 Paris, France; bourcier@quinze-vingts.fr

Accepted for publication 2 February 2003

\section{References}

1 Sharma N, Vajpayee RB, Pushker N, et al Infectious crystalline keratopathy. CLAO J 2000;26:40-3.

2 Gorovoy MS, Stern GA, Hood Cl, et al. Intrastromal noninflammatory bacterial colonization of a corneal graft. Arch Ophthalmol 1983;101:1749-52.

3 Wilhelmus KR, Robinson NM. Infectious crystalline keratopathy caused by Candida albicans. Am J Ophthalmol 1991;112:322-5.

4 Rhem MN, Wilhelmus KR, Font RL. Infectious crystalline keratopathy caused by Candida parapsilosis. Cornea 1996:15:543-5.

5 Khater TT, Jones DB, Wilhelmus KR. Infectious crystalline keratopathy caused by gram-negative bacteria. Am J Ophthalmol 1997; 124:19-23. 


\section{Rosai Dorfman disease or sinus histiocytosis with massive lymphadenopathy of the orbit}

Sinus histiocytosis with massive lymphadenopathy (SHML) or Rosai Dorfman syndrome is a rare benign proliferative histiocytic disease of unknown origin. It predominantly affects the lymph nodes. The head and neck region usually in association with lymph node involvement, represents one of the most common extranodal areas affected by SHML. The other common extra nodal site is skin. Rarely, there is widespread dissemination with liver kidney, respiratory organs, orbit, and eyeball involvement. ${ }^{1}$ The mean age of onset is 20 years (birth to 74 years)

\section{Case report}

A 57 year old woman with a 6 month history of double vision was referred to the Royal Victoria Eye and Ear Hospital, Dublin. She was found to have proptosis, ptosis, diplopia due to inferior rectus dysfunction, and restriction of elevation of the left eye. Her visual acuity was normal. Relevant investigations showed high erythrocyte sedimentation rate (ESR) of $44 \mathrm{~mm}$ in the first hour, $\mathrm{C}$ reactive protein of 1.9 (normal less than 1). Her thyroid function tests, including thyroid microsomal and thyroglobulin antibodies, were normal. The an tiacetyl choline receptor antibodies were also negative. A computed tomograph (CT) scan of the orbit was performed which showed an extraconal soft tissue mass with well defined margins in the inferomedial part of the left orbit and no separation from inferior and medial rectus. There was no bony erosion and the optic nerve appeared normal. She had an excision biopsy performed through latera orbitotomy with Wright's modification.

The tumour was removed within the capsule, it was found to be adherent to the inferior and lateral rectus. Histological examination of the tumour revealed an inflammatory process composed of aggregates of lymphocytes, with reactive lymphoid follicles, plasma cells, and groups of large histiocyte with abundant foamy cytoplasm. The inflammatory process extended around the nerves. There was no vasculitis, areas of coagulative necrosis, or granuloma formation. The large histiocytic cells were characterised by round to oval vesicular, hypochromatic nuclei with vesicular chromatin and abundant eosinophilic, foamy or clear cytoplasm with poorly defined cell borders. Emperipolesis was present. The phagocytosed cells were most often erythrocytes, lymphocytes, and polymorphonuclear leucocytes (Fig 1). Special stains for micro-organisms were negative. Immunohistochemical stains revealed the presence of diffuse S100 positivity within the cells. These cells also showed reactivity for the macrophage marker CD68. The diagnosis of Rosai Dorfman disease or SHML was confirmed.

Our patient did not have any lymphadenopathy or any other extranodal involvement. She did not receive any treatment and after 3 years' follow up there was no sign of recurrence. She still had some residual hypotropia.

\section{Comment}

We report this case to draw attention to this unusual presentation of SHML confined to the orbit without any extranodal lesions, which to our knowledge is the only the third reported case of this nature. SHML is a rare, benign proliferative histiocytic disease with massive lymphadenopathy. Table 1 lists the causes of histiocytic proliferations in the orbit.

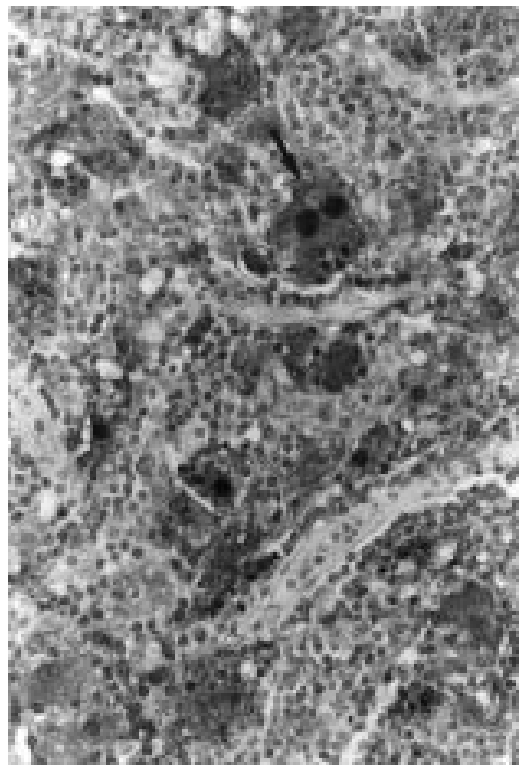

Figure 1 Sinus histiocytosis. A lymphoid infiltrate surrounding scattered large histiocytic cells containing phagocytosed intracytoplasmic lymphocytes (arrows) is seen. Original magnification $\times 200$.

In one report of SHML, uveitis with papilloedema was the only presentation and in another report the only site of the lesion was lacrimal sac with the duct but these patients later developed cervical lymphadenopathy..$^{23}$ Another case with ocular involvement was reported with uveitis and marginal corneal infiltrates in association with cervical lymphadenopathy. ${ }^{4}$ SHML is usually benign, low grade, and self limiting but death has been infrequently attributed to it. The condition has also been occasionally associated with the development of malignant lymphoma. Hodgkin's and the follicular type of non-Hodgkin's lymphoma and SHML have been identified in the same lymph node biopsy specimen. ${ }^{56}$ SHML may be associated with fever, leucocytosis, elevated erythrocyte sedimentation rate, and hypergammaglobulinaemia. Some studies suggest that human herpes virus (HHV-6) may play a part in pathogenesis of SHML. ${ }^{7} \mathrm{HHV}-6$ which infects many in childhood and remains latent in host cells can be reactivated by immunodeficiency. Serological evidence of HHV-6 and EpsteinBarr virus infection have also been documented in patients with SHML with their presence in affected tissues as well. ${ }^{7}$ SHML is usually self limiting but in some cases there was orbital involvement with compressive optic neuropathy, persistent uveitis with marginal corneal infiltrates, massive lymphadenopathy impairing cervical perfusion,

Table 1 Orbital histiocytic proliferations

Secondary to ruptured cyst or trauma Sinus histiocytosis with massive lymphadenopathy Necrobiotic xanthogranuloma

Erdheim-Chester disease

Juvenile and adult xanthogranuloma Langerhan's cell histiocytosis Familial haemophagocytic lymphohistiocytosis True histiocytic lymphoma and generalised lymphadenopathy with AA amyloidosis. These cases were treated with chemotherapy and oral steroids, the commonest being cyclophosphamide, vincristine, mercaptopurine, and prednisolone. Treatment causes regression of the tumour and resolution of cervical lymphadenopathy with minimal recurrence. ${ }^{89}$ Our patient did not receive any treatment and in the 3 year follow up there was no evidence of recurrence of the disease in the orbit or any sign of sinus histiocytosis elsewhere in the body.

R Khan, P Moriarty

Department of Ophthalmology, Royal Victoria Eye and Ear Hospital, Dublin, Ireland

S Kennedy

National Ophthalmic Pathology Laboratory, Royal Victoria Eye and Ear Hospital, Dublin, Ireland Correspondence to: Dr Khan, Department of Ophthalmology, Royal Victoria Eye and Ear Hospital, Dublin, Ireland

Accepted for publication 9 September 2002

\section{References}

1 Silvestre JF, Aliga A. Cutaneous sinus histiocytosis and chronic uveitis. Paediatr Dermatol 2000;17:377-80.

2 Dolman PJ, Harris GJ, Weiland LH. Sinus histiocytosis involving the lacrimal sac and duct. Arch Ophthalmol 1992;1 10:448-9.

3 Pivetti-Pezzi P, Torce C, Collabi-Gisoldi RA

Relapsing bilateral uveitis and papilloedema in sinus histiocytosis with massive lymphadenopathy (Rosai Dorfman syndrome) Eur J Ophthalmol 1995;5:59-62.

4 Rumelt S, Cohen I, Rehany U. Marginal corneal infiltrates a possible new manifestation of sinus histiocytosis with massive lymphadenopathy. Cornea 2000;1 9:857-8.

5 Lu D, Estililla OC, Manning JT Jr. Sinus histiocytosis with massive lymphadenopathy and malignant lymphoma involving the same lymphnode. Mod Path 2000;13:414-19.

6 Krezmiecki K, et al. The Rosai Dorfman syndrome in a 17 year old girl with transformation to high grade lymphoma. Ann Oncol 1996;9:977-9.

7 Levine PH, Jaffe ES. Detection of human herpes virus 6 it tissues involved by sinus histiocytosis with massive lymphadenopathy. $J$ Infect Dis 1992;166:291-5.

8 Rocken C, Weiker K, Grote HJ, et al. Rosai Dorfman syndrome with generalized AA amyloidosis. Hum Pathol 2000;31:621-4.

9 Goldberg S, Mahadevia P, et al. Sinus histiocytosis with massive lymphadenopathy involving the orbit: reversal of compressive optic neuropathy after chemotherapy. $J$ Neuro-ophthalmol 1998;18:270-5.

\section{CORRECTION}

The authors wish to correct an error in the article: A Comparison of Perimetric Results with Medmont and Humphrey Perimeters. (Br J Ophthalmol 2003:87:690-4). Table 4, row 1 , column 4 should read 1 not 2, and row 2, column 4 should read 35 not 34 . Table 6 , row 3 , column 1 should read 24 not 27, and row 4 , column 2 should read 27 not 24 .

\section{NOTICES}

\section{Helping the blind and visually} impaired

The latest issue of Community Eye Health (No 45) discusses help for the blind, with an editorial by Sir John Wall of the Royal National Institute for the Blind on the rights of blind people. For further information 
please contact: Journal of Community Eye Health, International Resource Centre, International Centre for Eye Health, Department of Infectious and Tropical Diseases, London School of Hygiene and Tropical Medicine, Keppel Street, London WCIE 7HT, UK (tel: +44 (0)20 7612 7964; email: Anita.Shah@ lshtm.ac.uk; website: www.jceh.co.uk). Annual subscription (4 issues) UK£28/US\$45. Free to developing country applicants.

\section{Second Sight}

Second Sight, a UK based charity whose aims are to eliminate the backlog of cataract blind in India by the year 2020 and to establish strong links between Indian and British ophthalmologists, is regularly sending volunteer surgeons to India. Details can be found at the charity's website (www.secondsight.org.uk) or by contacting Dr Lucy Mathen (lucymathen@yahoo.com).

\section{SPecific Eye ConditionS (SPECS)}

SPecific Eye ConditionS (SPECS) is a not for profit organisation which acts as an umbrella organisation for support groups of any conditions or syndrome with an integral eye disorder. SPECS represents over 50 different organisations related to eye disorders ranging from conditions that are relatively common to very rare syndromes. The website acts as a portal giving direct access to support groups own sites. The SPECS web page is a valuable resource for professionals and may also be of interest to people with a visual impairment or who are blind. For further details abou SPECS contact: Kay Parkinson, SPECS Development Officer (tel: +44 (0)1803 524238; email: k@eyeconditions.org.uk; website www.eyeconditions.org.uk)

\section{The British Retinitis Pigmentosa Society}

The British Retinitis Pigmentosa Society (BRPS) was formed in 1975 to bring together people with retinitis pigmentosa and their families. The principle aims of BRPS are to raise funds to support the programme of medical research into an eventual cure for this hereditary disease, and through the BRPS welfare service, help members and their families cope with the everyday concerns caused by retinitis pigmentosa. Part of the welfare service is the telephone help line $(+44$ (0) 1280860363 ), which is a useful resource for any queries or worries relating to the problems retinitis pigmentosa can bring. This service is especially valuable for those recently diagnosed with retinitis pigmentosa, and all calls are taken in the strictest confidence. Many people with retinitis pigmentosa have found the Society helpful, providing encouragement, and support through the Help line, the welfare network and the BRPS branches throughout the UK (tel: +44 (0)1280 821 334; email: lynda@brps.demon.co.uk; website: www.brps.demon.co.uk).

\section{Surgical Eye Expeditions International}

Volunteer ophthalmologists in active surgical practice are needed to participate in short term, sight restoring eye surgery clinics around the world. Contact: Harry S Brown, Surgical Eye Expeditions International, 27 East De La Guerra, C-2, Santa Barbara, CA 93101-9858, USA (tel: +805 963 3303; fax: +805 965 3564; email: hsbrown.md@cox.net or seeintl@seeintl.org; website: www.seeintl. org).

\section{Rise in organ transplant numbers}

According to UK Transplant, the UK has seen the highest number of organ transplants in six years. Last year (1 April 2002 to 31 March 2003) 2777 patients had their lives saved or dramatically improved through the generosity of 1064 donors. This equated to a $6 \%$ increase compared to the previous 12 months ( 1 April 2001 to 31 March 2002). Furthermore during 2002-3, the highest number of people benefited from a cornea transplant for five years (1997-98) and 240 more people had their sight restored than the previous year. For further information see UK Transplant's website (www.uktransplant.org.uk).

\section{Elimination of avoidable \\ blindness}

The 56th World Health Assembly (WHA) considered the report on the elimination of avoidable blindness (doc A56/26) and urged Member States to: (1) Commit themselves to supporting the Global Initiative for the Elimination of Avoidable Blindness by setting up a national Vision 2020 plan by 2005; (2) Establish a national coordinating committee for Vision 2020, or a national blindness prevention committee to help implement the plan (3) Implement the plan by 2007 ; (4) Include effective monitoring and evaluation of the plan with the aim of showing a reduction in the magnitude of avoidable blindness by 2010; (5) To support the mobilisation of resources for eliminating avoidable blindness. The WHA also urged the Director-General to maintain and strengthen WHO's collaboration with Member States and the partners of the Global Initiative for the Elimination of Avoidable Blindness as well as aid in the coordination and support of national capability.

\section{MSc course in Community Eye Health}

The International Centre for Eye Health is offering a full time MSc course in Community Eye Health from 29 September 2003 to 19 September 2004. The course is not clinical and is specifically for eye health professionals wanting to work in the field of community eye health. The course is designed in keeping with the aims, priorities, and strategies of Vision 2020 - the Right to Sight. The course costs $£ 3939$ for home students and $£ 14110$ for overseas students. Further information: The Registry, 50 Bedford Square, London WC1B 3DP, UK (tel: +44 (0)20 7927 2239; fax: +44 (0)20 7323 0638; email: Adrienne.Burrough@1shtm.ac.uk; website: www.lshtm.ac.uk).

\section{Ophthalmic Anesthesia Society (OAS) - 17th Scientific Meeting}

The 17th Scientific Meeting of the Ophthalmic Anesthesia Society (OAS) will be held 3-5
October 2003 at the Westin Michigan Avenue Chicago, Chicago, USA. Programme co-chairs: Marc Allen Feldman MD MHS and Steven T Charles MD. The CME joint sponsor is the Cleveland Clinic Foundation; CME hours are pending. Fees for OAS members are \$300; non-members \$475; students \$50.

Further details: OAS, 793-A Foothill Blvd, PMB 119, San Luis Obispo, CA 93405 USA (tel: + 1805534 0300; fax: + 1805534 9030; email: info@eyeanesthesia.org; website: www.eyeanesthesia.org).

\section{Glaucoma Society 24th Annual Meeting and Dinner}

The Glaucoma Society 24th Annual Meeting and Dinner will take place on 20 November 2003, from 8:30 am to $5: 00 \mathrm{pm}$ at The Royal College of Physicians, London, UK. Further details: Ms Janet Flowers (email: glausoc@ukeire.freeserve.co.uk).

\section{Detachment Course with international faculty on: Retinal and Vitreous Surgery with Case Presentations preceding the Annual Meeting of Iranian Society of Ophthalmology}

The detachment course with international faculty on: Retinal and Vitreous Surgery with Case Presentations preceding Annual Meeting of Iranian Society of Ophthalmology will be held on 29-30 November 2003 and 1-4 December 2003 respectively, at the Razi Conference Center, Hemmat Hyw, Tehran, Iran. Further details: Scientific programme: Prof Ingrid Kreissig, University of Tuebingen, Schleichstr. 12, Breuningerbau, 72076 Tuebingen, Germany (tel: +49 7071 295209; email: ingrid.kreissig@med.uni-tuebingen.de).

Local organisation: Dr Arman Masheyekhi, Dr Siamak Moradian, Dept of Ophthalmology, Labbanfinejad Medical Center, Pasdaran Ave, Boostan 9, Tehran, 16666, Iran (fax: +98 21 254 9039; email: labbafi@hotmail.com).

\section{5th International Symposium on Ocular Pharmacology and Therapeutics (ISOPT)}

The 5th International Symposium on Ocular Pharmacology and Therapeutics (ISOPT) will take place 11-14 March 2004, in Monte Carlo, Monaco. Please visit our website for details of the scientific programme, registration, and accommodation. To receive a copy of the Call for Abstracts and registration brochure please submit your full mailing details to http:// www.kenes.com/isopt/interest.htm.

Further details: ISOPT Secretariat (website: www.kenes.com/isopt).

\section{XVth Meeting of the International} Neuro-Ophthalmology Society

The XVth Meeting of the International NeuroOphthalmology Society will take place 18-22 July 2004, in Geneva, Switzerland.

Further details: Prof. A Safran, University Hospital Geneva, c/o SYMPORG SA, Geneva (fax: +4122 839 8484; email: info@ symporg.ch; website: www.symporg.ch). 